\title{
ACCOUNTS
}

of chemical research

pubs.acs.org/accounts

\section{N-Heterocyclic Carbenes: A Door Open to Supramolecular Organometallic Chemistry}

\author{
3 Susana Ibáñez, Macarena Poyatos, and Eduardo Peris*
}

Cite This: https://dx.doi.org/10.1021/acs.accounts.0c00312

Read Online

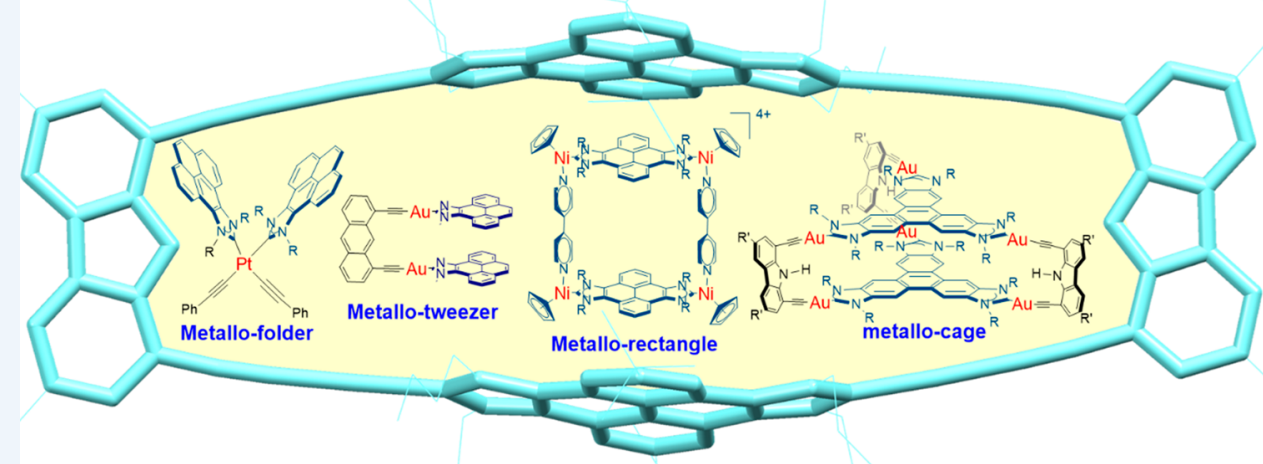

4 CONSPECTUS: The field of metallosupramolecular chemistry is clearly dominated by the use of O- N-, and P-donor Werner-type 5 polydentate ligands. These molecular architectures are of high interest because of their wide range of applications, which include 6 molecular encapsulation, stabilization of reactive species, supramolecular catalysis, and drug delivery, among others. Only recently, 7 organometallic ligands have allowed the preparation of a variety of supramolecular coordination complexes, and the term 8 supramolecular organometallic complexes (SOCs) is gaining space within the field of metallosupramolecular chemistry. While the 9 early examples of SOCs referred to supramolecular architectures mostly containing bisalkenyl, diphenyl, or bisalkynyl linkers, the 10 development of SOCs during the past decade has been boosted by the parallel development of multidentate N-heterocyclic carbene 11 (NHC) ligands. The first examples of NHC-based SOCs referred to supramolecular assemblies based on polydentate NHC ligands 12 bound to group 11 metals. However, during the last 10 years, several planar poly-NHC ligands containing extended $\pi$-conjugated 13 systems have facilitated the formation of a large variety of architectures in which the supramolecular assemblies can contain metals 14 other than $\mathrm{Cu}, \mathrm{Ag}$, and $\mathrm{Au}$. Such ligands are Janus di-NHCs and trigonal-planar tris-NHCs-most of them prepared by our research 15 group - which have allowed the preparation of a vast range of NHC-based metallosupramolecular compounds with interesting host16 guest chemistry properties. Although the number of SOCs has increased in the past few years, their use for host-guest chemistry 17 purposes is still in its earliest infancy. In this Account, we describe the achievements that we have made during the last 4 years 18 toward broadening the applications of planar extended $\pi$-conjugated NHC ligands for the preparation of organometallic-based 19 supramolecular structures, including their use as hosts for some selected organic and inorganic guests, together with the catalytic 20 properties displayed by some selected host-guest inclusion complexes. Our contribution describes the design of several Ni-, Pd-, and $21 \mathrm{Au}$-based metallorectangles and metalloprisms, which we used for the encapsulation of several organic substrates, such as polycyclic 22 aromatic hydrocarbons (PAHs) and fullerenes. The large binding affinities found are ascribed to the incorporation of two cofacial 23 panels with large $\pi$-conjugated systems, which provide the optimum conditions for guest recognition by $\pi$ - $\pi$-stacking interactions. 24 We also describe a series of digold(I) metallotweezers for the recognition of organic and inorganic substrates. These metallotweezers 25 were used for the recognition of "naked" metal cations and polycyclic aromatic hydrocarbons. The recognition properties of these 26 metallotweezers are highly dependent on the nature of the rigid connector and of the ancillary ligands that constitute the arms of the 27 tweezer. A peculiar balance between the self-aggregation properties of the tweezer and its ability to encapsulate organic guests is 28 observed.

\section{INTRODUCTION}

29 Metallosupramolecular chemistry refers to the field of research 30 involving the combination of bridging organic ligands with metal 31 units that form discrete or polymeric assemblies of different 32 shapes and sizes. ${ }^{1}$ Over the last three decades, coordination33 driven self-assembly has become a widespread strategy for the
Received: $\quad$ May 22, 2020 
Scheme 1. Some NHC-Based SOCs with Group 11 Metals

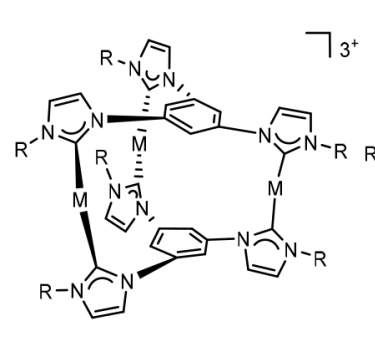

$\mathrm{M}=\mathrm{Ag}, \mathrm{Au}, \mathrm{Cu}$

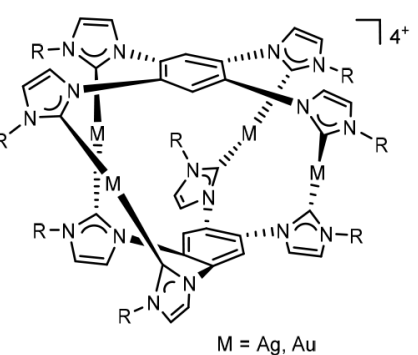

$\mathrm{M}=\mathrm{Ag}, \mathrm{Au}$

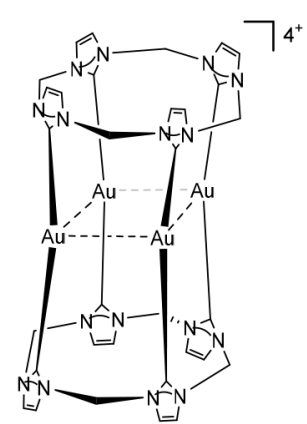

$\overbrace{3^{+}}$

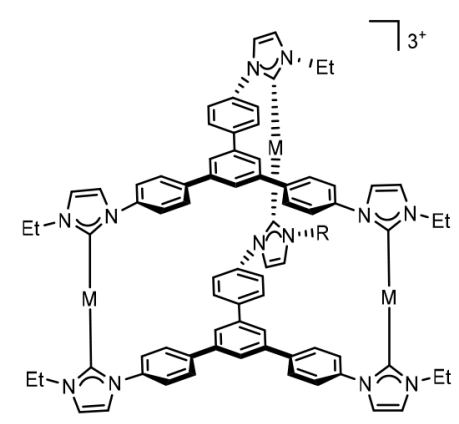

$\mathrm{M}=\mathrm{Cu}, \mathrm{Ag}, \mathrm{Au}$

\section{Scheme 2. Planar Di- and Tri-NHC Ligands for the Preparation of SOCs}

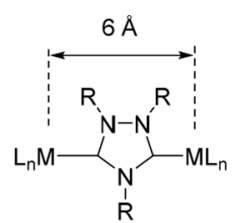

A, Peris, 2007

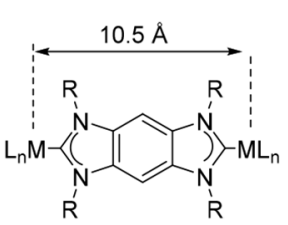

B, Bielawski, 2006

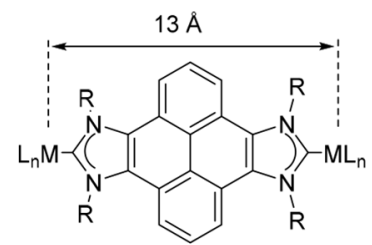

C. Peris, 2014

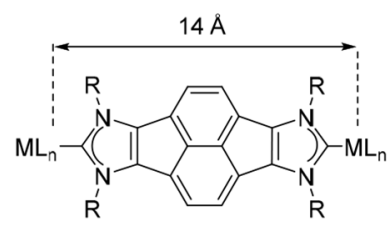

D, Peris, Alcarazo 2012

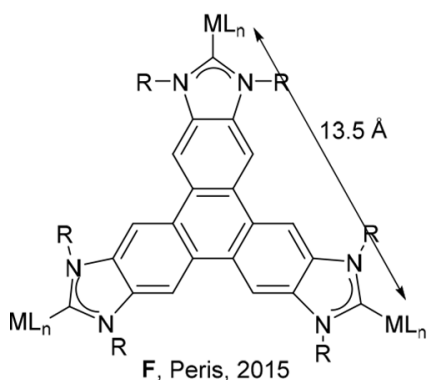

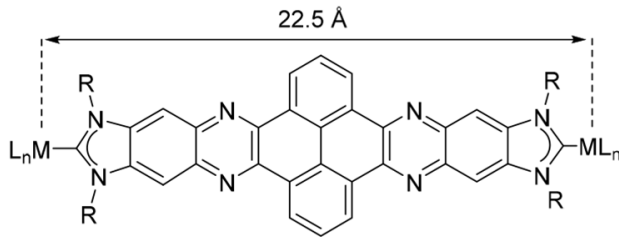

E, Peris, 2007

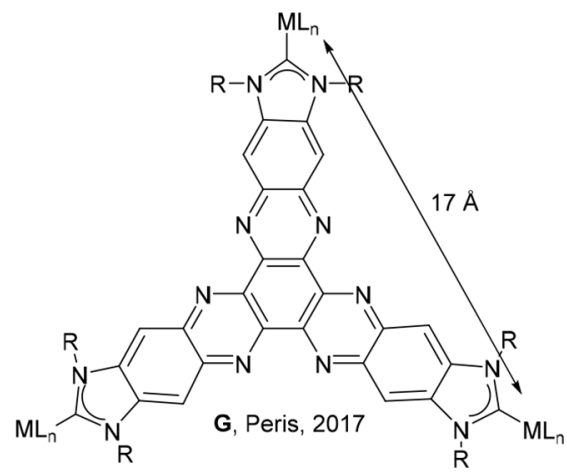

34 rational construction of discrete supramolecular coordination 35 complexes (SCCs). ${ }^{1 \mathrm{a}, 2}$ This technique capitalizes on the 36 directional and predictable nature of the metal-ligand bond, 37 which allows the outcome of the self-assembly process to be 38 predicted with a high level of certainty. Many of the reported 39 SCCs have discrete void areas with well-defined shapes and sizes, and this is why SCCs are often called "molecular flasks". ${ }^{3} 40$ These cavities impart unique properties to the structure that lead 41 to novel functions and applications. For the design of these void 42 spaces, the ligand is arguably the most important building block 43 because its topological features and binding abilities determine 44 the size, geometry, and functionality of the resulting cavities. 45 
46 From the ligand perspective, metallosupramolecular chemistry 47 is clearly dominated by the use of $\mathrm{O}-, \mathrm{N}$-, and $\mathrm{P}$-donor Werner48 type polydentate ligands, while only a few examples of 49 assemblies bearing carbon donor ligands have been reported 50 in the literature. However, during the past decade, the number of 51 organometallic-based supramolecular assemblies has grown fast 52 and parallel to the development of multidentate $\mathrm{N}$-heterocyclic 53 carbene (NHC) ligands, ${ }^{4}$ and a number of review articles were 54 published recently. ${ }^{5}$ The rapid development of supramolecular 55 assemblies with organometallic ligands is exemplified by the 56 establishment of the term supramolecular organometallic 57 complexes (SOCs), coined by Pöthig and Casini in $2019,{ }^{5 \mathrm{c}}$ to 58 refer to complexes in which the (organic) linker forms the 59 organometallic bond to the metal node. This means that the 60 carbon-metal bond is structurally crucial for the formation of 61 the architecture of the resulting SOC, in contrast to those 62 assemblies that do not have organometallic-based ligands or 63 those whose organometallic ligands (normally $\eta^{5}-\mathrm{Cp}$ or $\eta^{6}$ 64 arene) cap the metal nodes.

65 Most NHC-based SOCs are supramolecular assemblies based 66 on polydentate NHC ligands bound to group 11 metals. The 67 reason for this is that these metals often display linear 68 coordination modes that facilitate trans coordination of the $69 \mathrm{NHC}$ ligands, thereby forming assemblies in which the metal 70 atoms are sandwiched between the two polydentate NHC 71 ligands. In addition, the $\mathrm{NHC}-\mathrm{M}$ bond $(\mathrm{M}=\mathrm{Cu}, \mathrm{Ag}, \mathrm{Au})$ is 72 usually labile, which allows the formation of the thermodynami73 cally most stable assemblies from mixtures of the metal 74 precursors and the poly-NHC. These assemblies include 75 rectangles, triangles, ${ }^{6}$ and cylinders, ${ }^{7}$ such as the ones shown 76 in Scheme 1.

77 However, during the last 10 years, several planar poly78 conjugated poly-NHC ligands have facilitated the formation of a

79 variety of structures in which the supramolecular assemblies can 80 contain metals other than $\mathrm{Cu}, \mathrm{Ag}$, and $\mathrm{Au}^{8}{ }^{8}$ The use of the Janus 81 di-NHC ligands A-E (Scheme 2) allows the synthesis of 82 supramolecular assemblies whose dimensions may range from 6 $83 \AA$ as established by triazolylidene ligand $\mathrm{A}^{8 \mathrm{a}}$ to almost $23 \AA$ when 84 the nanosized di-NHC with the quinoxalinophenanthrophena85 zine core $\mathbf{E}^{8 \mathrm{e}}$ is used. Among these, the benzobis86 (imidazolylidene) ligand $\mathbf{B}$ described by Bielawski in $2005^{9}$ 87 was the first one to demonstrate its suitability for the preparation 88 of organometallic-based assemblies. Some threefold-symmetric 89 tri-NHCs, such as $\mathbf{F}$ and $\mathbf{G}$, have also been prepared. ${ }^{8 \mathrm{~d}, \mathrm{f}, 10}$

90 Hahn's group was the first one to exploit the linear 91 arrangement of $\mathbf{B}$ for the preparation of a number of square92 and rectangular-shaped assemblies that included metals such as 93 gold $^{11}$ iridium, ${ }^{12}$ platinum, ${ }^{13}$ palladium, ${ }^{12 \mathrm{~b}}$ and nickel ${ }^{14}$ 94 (Scheme 3). Together with the use of this benzobis95 (imidazolylidene) ligand, Hahn also used a structurally similar $96 \mathrm{di}(\mathrm{NH}, \mathrm{O})-\mathrm{NHC}$ ligand for the preparation of a large number of 97 molecular squares. ${ }^{6, \mathrm{~b}}$ The benzobis(NHC) ligand $\mathbf{B}$ establishes 98 a metal-to-metal separation of $10.5 \AA$, which in most cases is too 99 small to build cavities of the appropriate size to host organic 100 guests. This is probably the reason why none of the 101 organometallic assemblies displayed in Scheme 3 were used 102 for host-guest chemistry purposes.

103 Although the number of SOCs has increased in the past few 104 years, those used for host-guest chemistry purposes are still very 105 few. Some recent relevant examples of SOCs used for the 106 encapsulation of organic substrates were described by Altmann 107 and Pöthig, ${ }^{15}$ who developed organometallic-based rotaxanes 108 consisting of $\mathrm{Ag}_{8}$ and $\mathrm{Au}_{8}$ pillarplexes, which are highly selective
Scheme 3. NHC-Based Metallosquares Described by Hahn's Group
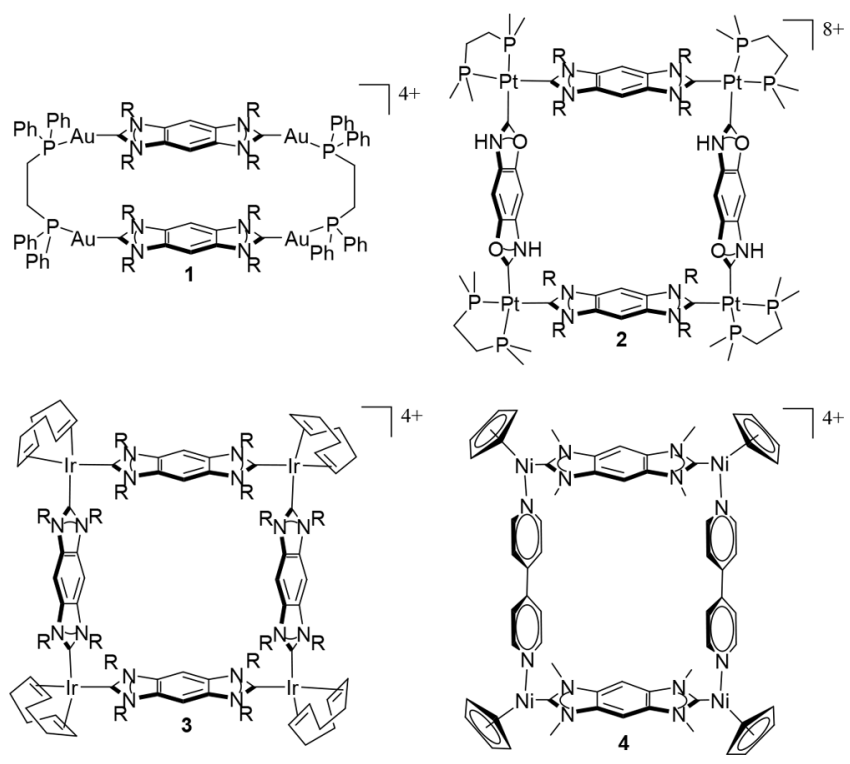

for the encapsulation of linear molecules, such as 1,8-109 diaminooctane. These metallosupramolecules also showed 110 important antimicrobial activity and anticancer properties. ${ }^{16} \quad 111$

With all of these precedents in hand, 4 years ago we started a 112 new research line aiming to provide effective synthetic routes to 113 NHC-based SOCs with applications in catalysis and host-guest 114 chemistry. A clear advantage for us is that during the past few 115 years we have prepared a large number of planar di- and tri-NHC 116 ligands bearing $\pi$-extended polyconjugated cores such as those 117 shown in Scheme 2, so we thought that this placed us in a 118 privileged position to approach this new research line. In 119 addition, our previous studies on the influence of supra- 120 molecular interactions on homogeneously catalyzed reactions ${ }^{17} 121$ had already constituted our initial approach to metallosupra- 122 molecular chemistry and thus gave us some expertise in the field. 123 This Account focuses on our achievements in the development 124 of NHC-based SOCs that we prepared during the last 4 years, 125 emphasizing their use as hosts for some selected organic and 126 inorganic guests. The Account thus covers our progress in the 127 development of several Ni-, Pd-, and Au-based metallorectan- 128 gles, metalloprisms, and metallotweezers together with their 129 respective host-guest chemistry properties.

130

\section{STRUCTURES WITH MONO-NHC LIGANDS: METALLOFOLDERS AND METALLOTWEEZERS}

A molecular tweezer is a molecular receptor that contains two 132 identical flat polyaromatic arms at the edges that are connected 133 in a syn conformation by a more-or-less rigid tether (Scheme $134 \mathrm{~s} 4$ 4). ${ }^{18}$ In order to enable complexation with aromatic substrates $135 \mathrm{~s} 4$ by $\pi-\pi$-stacking interactions, the two parallel polyaromatic 136 hands should be ideally separated by $\sim 7 \AA$, as aromatic groups 137 stack at an interplanar distance of $\leq 3.5 \AA$.

138

While molecular tweezers were initially based on organic 139 entities, in the past decade some research groups have 140 incorporated metals into the structure of the tweezers, thus 141 introducing a new dimension into the properties of these 142 supramolecular systems. ${ }^{19}$ Our first approach to the develop- 143 ment of metallotweezers was the preparation of a series of $\mathrm{Pt}(\mathrm{II}) \quad 144$ complexes bearing cis-oriented NHC ligands decorated with $\pi$ - 145 s5 
Scheme 4. Schematic Representation of a Molecular Tweezer Trapping a Molecule of Pyrene

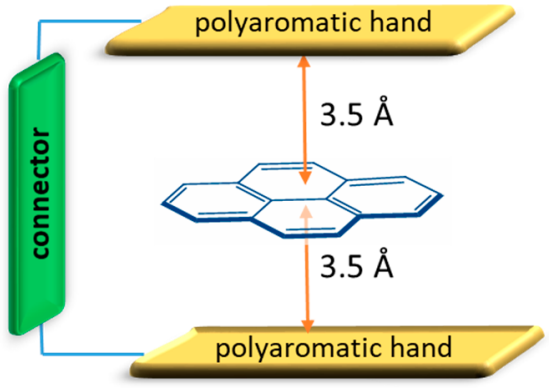

146 extended polyaromatic moieties (Scheme 5a). ${ }^{20}$ The orthogonal 147 disposition of the two aromatic hands of the receptor made us

Scheme 5. (a) Platinum-Based Metallofolders 5 and 6; (b) Guests Used in the Study; (c) Molecular Structure of TCNB@5

a)

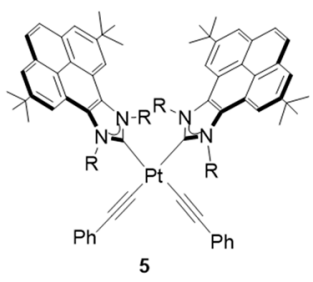

b)
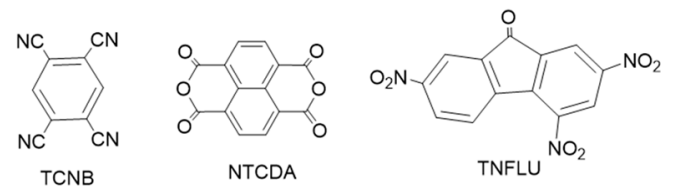

c)

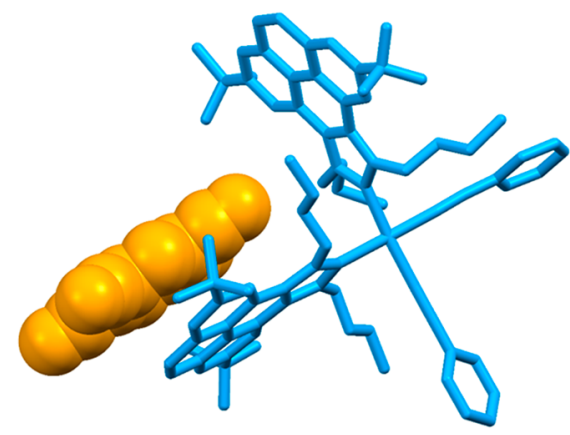

148 consider that the term metallofolders would be more accurate to 149 refer to this subclass of metallotweezers. By taking advantage of 150 the void space between the polyaromatic panels, these 151 complexes were used as receptors of electron-deficient organic 152 molecules such as 1,2,4,5-tetracyanobenzene (TCNB), 2,4,7153 trinitro-9-fluorenone (TNFLU), and 1,4,5,8-naphthalenetetra154 carboxylic dianhydride (NTCDA). Although the host-guest 155 association constants were low, we observed that the receptors 156 were able to discriminate between electron-rich and electron157 deficient aromatic substrates. Besides, we observed that 158 molecule 6 containing the phenanthrophenazine panel was a 159 more effective receptor than molecule 5 containing pyrene, most 160 likely because of the larger surface area provided by the former 161 one, which renders a more effective $\pi-\pi$-stacking interaction 162 with the guests. ${ }^{20}$ The relatively low binding affinities shown by these two receptors are due to the orthogonal disposition of the 163 two polyaromatic panels, which prevents their cooperative $\pi-\pi$ - 164 stacking interaction with the guests, as would have probably 165 happened if the two panels were disposed in a parallel manner. 166

Our next approach for the preparation of metallotweezers was 167 the synthesis of complex 7 (Scheme 6), which contains two $168 \mathrm{~s} 6$ $\mathrm{Au}(\mathrm{I})$ pyrene-imidazolylidene arms connected by a 1,8- 169 diethynylanthracene linker. ${ }^{21}$ In principle, this metallotweezer 170 should show interesting recognition abilities since the two 171 polyaromatic panels are parallel and separated by approximately 172 $7 \AA$ A. However, the supramolecular properties of 7 are markedly 173 determined by its tendency to self-aggregate. In a nonpolar 174 solvent such as benzene, 7 self-aggregates to form the duplex 175 complex $(7)_{2}$ (Scheme 6). This self-complementary duplex 176 complex is formed by the encapsulation of the anthracenyl linker 177 of each tweezer between the two pyrene-functionalized arms of 178 the complementary one. The molecular structure of the complex 179 shows that the four gold atoms form a rectangle displaying 180 strong aurophilic interactions between the pairs of gold atoms of 181 complementary tweezers. In the presence of "naked" metal 182 cations $\left(\mathrm{Cu}^{+}, \mathrm{Ag}^{+}\right.$, or $\left.\mathrm{Tl}^{+}\right)$, the tweezer is able to self-aggregate in 183 $\mathrm{CH}_{2} \mathrm{Cl}_{2}$, thus forming a similar duplex complex in which the 184 metal cation is trapped inside the small cavity formed by the 185 supramolecular assembly, as shown in Scheme 5 for the case of 186 the addition of $\mathrm{Ag}^{+}$. The self-aggregated structures formed are 187 stabilized by a combination of $\pi-\pi$-stacking and $\mathrm{M}-\mathrm{Au} 188$ metallophilic interactions. Titrations by fluorescence spectros- 189 copy allowed the determination of the large association 190 constants of the resulting inclusion duplex complexes formed 191 by addition of the metal cations. ${ }^{21}$

192

We were interested in studying how subtle modifications of 193 the structure of 7 would affect the supramolecular properties of 194 the resulting complex. We first obtained the new metallotweezer 195 8 (Scheme 7) in which we changed the pyrene-imidazolylidene $196 \mathrm{~s} 7$ ligand to a smaller benzoimidazolylidene. ${ }^{22}$ It was anticipated 197 that this would reduce the ability of the complex to self- 198 aggregate because the $\pi$-delocalized surface area of the ligand is 199 smaller than that shown by the pyrene-functionalized ligand in 7.200 In fact, we observed that in the absence of an external stimulus, 8201 does not show any tendency to self-aggregate. However, the 202 addition of $\mathrm{Cu}^{+}, \mathrm{Tl}^{+}$, or $\mathrm{Ag}^{+}$facilitated the formation of self- 203 aggregated structures in which the metal cations occupied the 204 cavity of the dimer, although the three different species showed 205 very distinctive behaviors. The complex with copper showed an 206 interesting naked-eye-perceivable color change response 207 (orange to yellow) to the presence of acetonitrile or ammonia 208 vapors. This color change reverts after a few minutes upon 209 exposure to air, and the process is fully reversible, as 210 demonstrated through numerous cycles. This reversible 211 vapochromism is explained by the formation of $[\mathrm{Cu}-212$ $\left.\left(\mathrm{CH}_{3} \mathrm{CN}\right)_{4}\right]\left(\mathrm{BF}_{4}\right)$ or $\left[\mathrm{Cu}\left(\mathrm{NH}_{3}\right)_{4}\right]\left(\mathrm{BF}_{4}\right)$ upon exposure of 213 $\mathrm{Cu} @(8)_{2}$ to vapors of acetonitrile and ammonia, respectively, 214 with the concomitant formation of $\mathbf{8}$. In addition, while solutions 215 of the thallium-trapped species Tl@(8) $)_{2}$ were stable for days, the 216 compounds containing copper and silver evolved into a polymer 217 $(\mathrm{Cu})$ or an oligomer $(\mathrm{Ag})$ (Scheme 7$).^{22}$ The different reactivity 218 patterns shown by 8 and the pyrene-containing tweezer 7 are 219 explained because $\pi-\pi$-stacking interactions are less likely to be 220 produced in $\mathbf{8}$, and therefore, the molecule may self-aggregate, 221 but the process is reversible and may also give rise to more 222 complex structures such as oligomers and polymers. 223

Once we studied the self-aggregation properties of tweezers 7224 and $\mathbf{8}$, we became interested in studying the cation-triggered 225 
Scheme 6. Self-Aggregation of 7 in Benzene and in the Presence of $\mathbf{A g}^{+}$

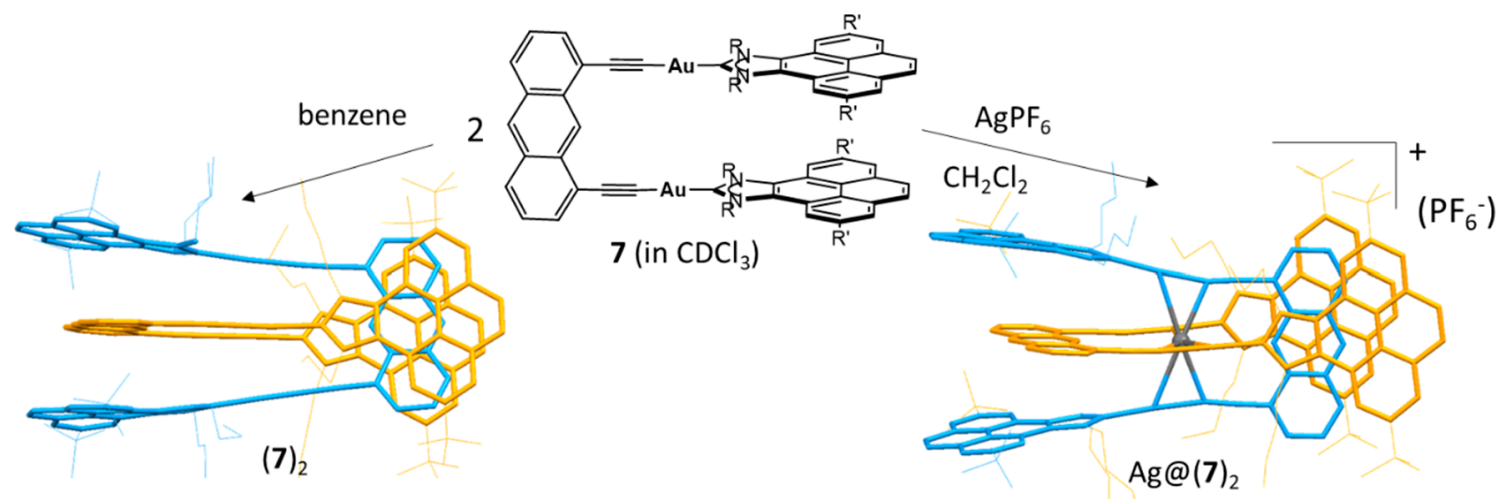

Scheme 7. Reactivity Shown by 8 upon Addition of $\mathrm{Cu}^{+}, \mathrm{Tl}^{+}$, or $\mathrm{Ag}^{+}$
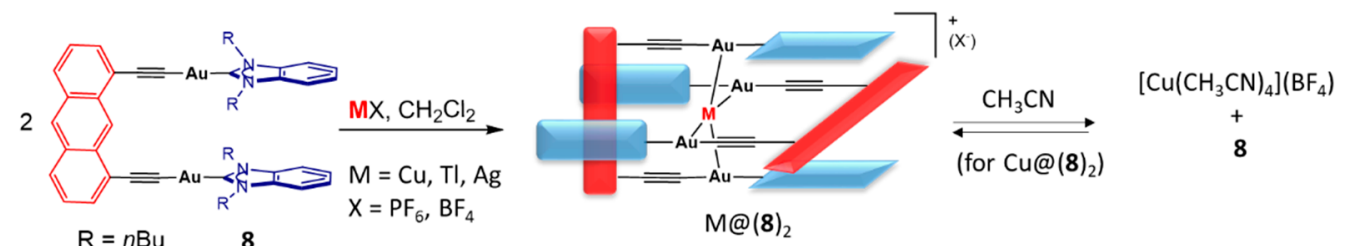

$\mathrm{R}=n \mathrm{Bu} \quad \mathbf{8}$

\begin{tabular}{l|l} 
Long standing solutions of $\mathrm{Cu}(8)_{2}$ & Long standing solutions of $\mathrm{Ag} @(8)_{2}$ \\
\hline
\end{tabular}
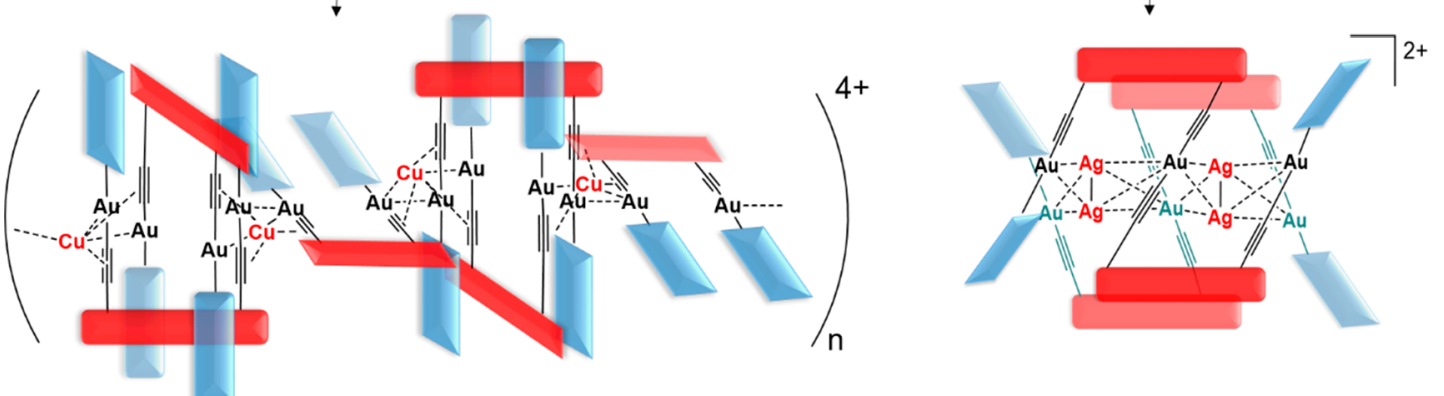

Scheme 8. Social Self-Sorting Involving Mixtures of Complexes 7 and 8

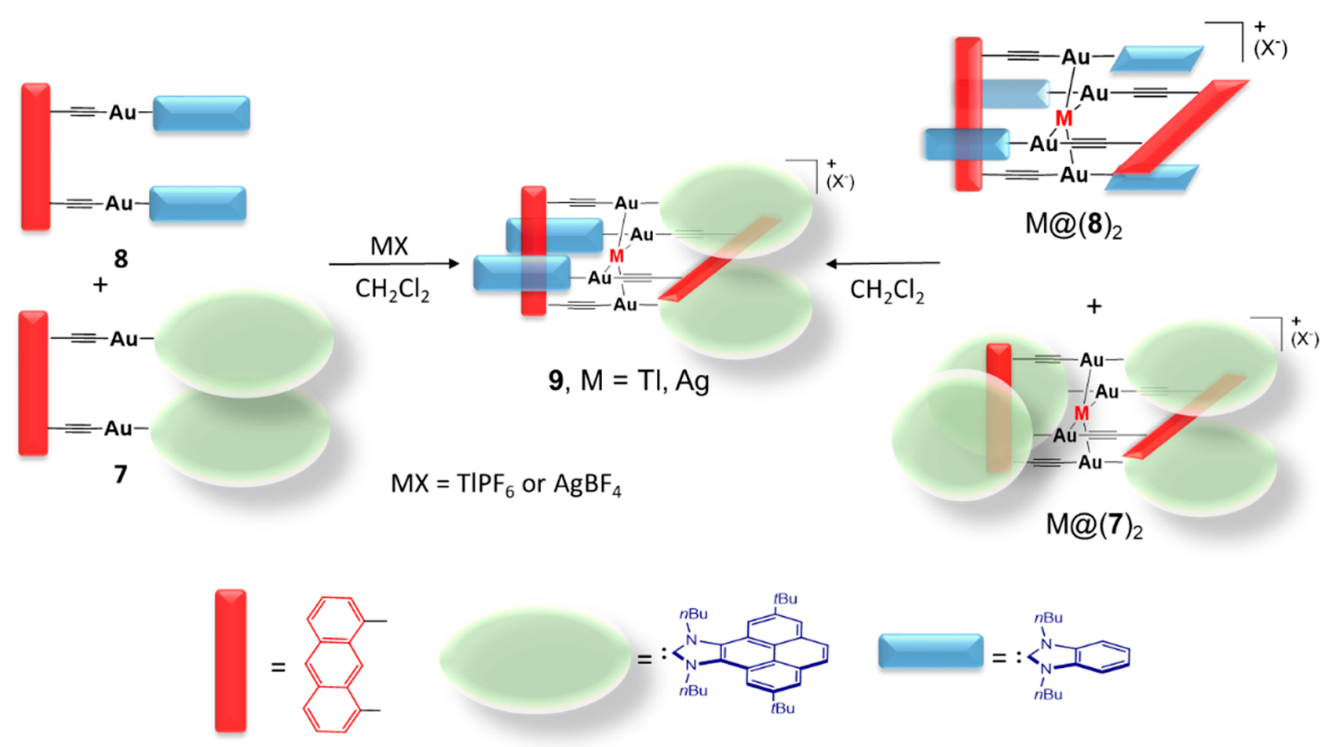

226 self-association properties of mixtures of these two different 227 metallotweezers in order to determine whether any selectivity was produced in the formation of the resulting molecular 228 aggregates. $^{23}$ As depicted in Scheme 8, the reactions of $229 \mathrm{~s} 8$ 
Scheme 9. Strategies for Avoiding the Self-Aggregation of Au(I) Metallotweezers

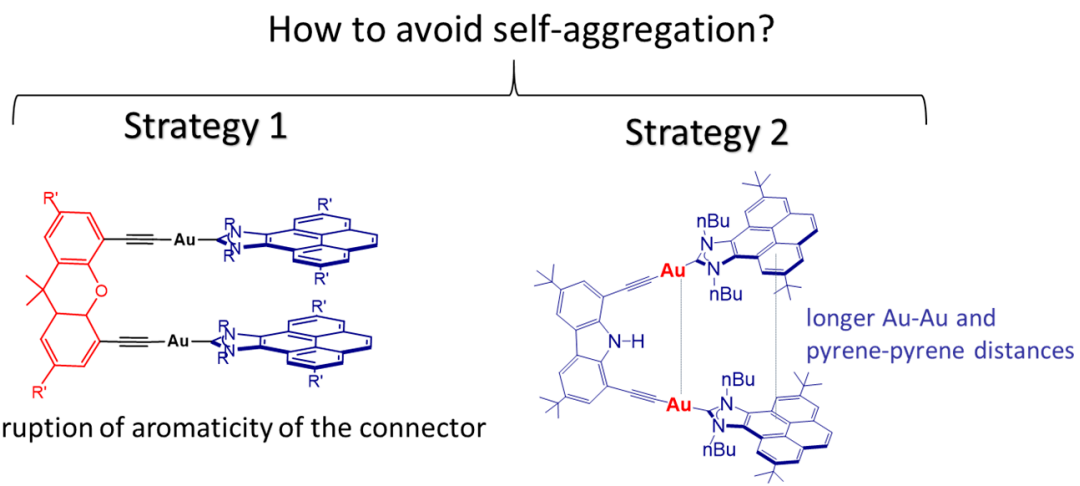

Separation of the arms of tweezer

Scheme 10. Distinct Coordination Modes of 10 with $\mathrm{Cu}^{+}, \mathrm{Tl}^{+}$, and $\mathrm{Ag}^{+}$

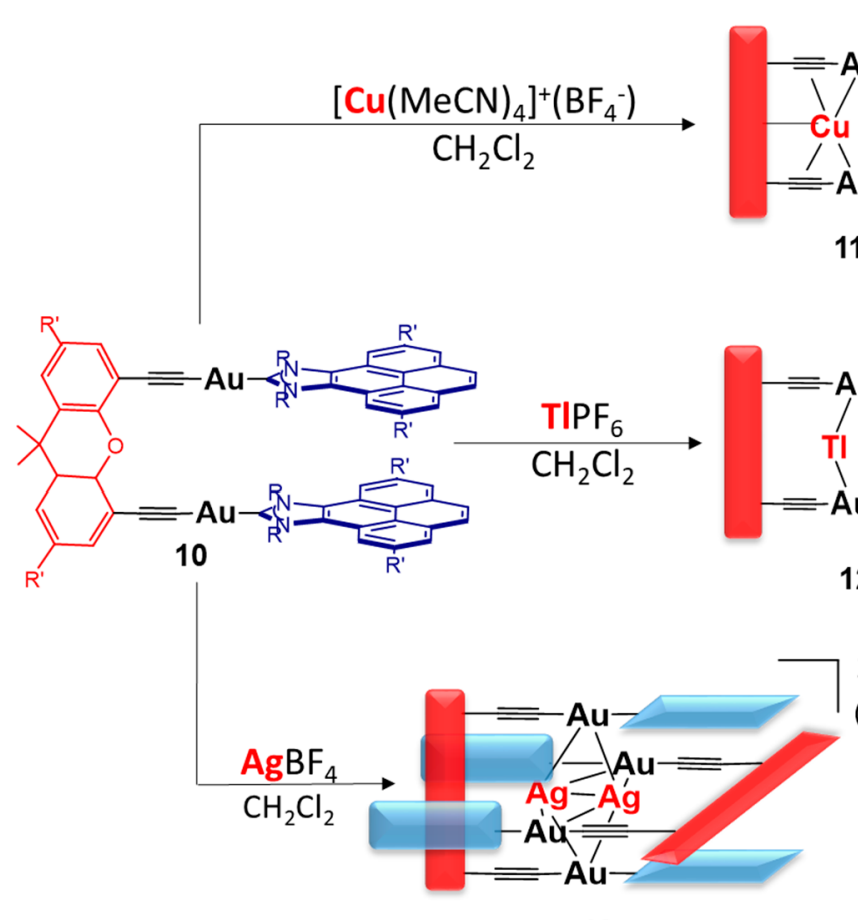

13

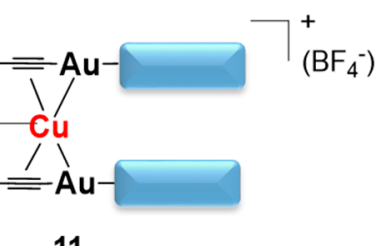

11

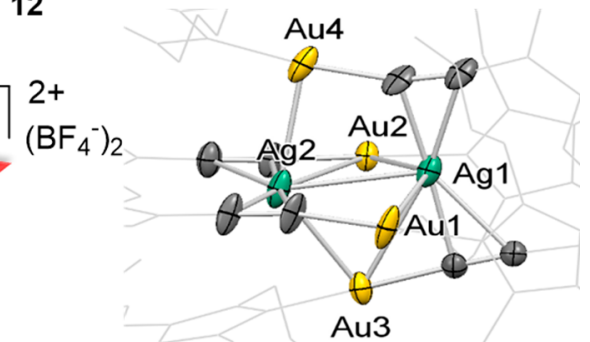

Core of the structure of 13
230 equimolar mixtures of 7 and $\mathbf{8}$ with $\mathrm{TlPF}_{6}$ or $\mathrm{AgBF}_{4}$ exclusively 231 yielded the heterocomplexes 9 , in which the two different 232 metallotweezers with the two different NHC-based ligands 233 aggregate, indicating that for this process the product was 234 obtained through a highly selective social self-sorting event. The 235 reactions between the homocomplex dimers containing thallium 236 or silver also evolved to the related mixed-ligand hetero237 complexes $\mathbf{9}$, thus indicating that 9 is the thermodynamically 238 (rather than kinetically) favored species. The formation of 9 was 239 assumed to be a consequence of the maximization of the $\pi-\pi$ 240 stacking and metallophilic interactions in the aggregated 241 structures. ${ }^{23}$ Other examples of self-sorting phenomena shown 242 by NHC-based assemblies have been reported recently. ${ }^{6 c, 24}$

243 As can be seen from the description of the properties of 7 and 244 8, it became evident that their supramolecular properties are 245 determined by their tendency to self-aggregate. In order to use a 246 metallotweezer for the recognition of aromatic substrates, we 247 needed to minimize the self-aggregation tendency so that the 248 two polyaromatic arms of the receptor would be exclusively used to trap a potential aromatic guest. In order to reduce the self- 249 complementary character of the tweezers, we thought of two 250 different strategies. The first involved designing a new 251 metallotweezer with a linker in which the $\pi$-extended system is 252 disrupted, so that its participation in the $\pi-\pi$-stacking event is 253 less likely to occur (Scheme 9, strategy 1). The second strategy $254 \mathrm{~s} 9$ consists of using a linker with two diverging alkynyl ligands, so 255 that the two polyaromatic arms of the tweezer are separated by a 256 distance that prevents their participation in the self-aggregation 257 process (Scheme 9, strategy 2).

To implement the first strategy, we prepared U-shaped digold 259 metallotweezer $\mathbf{1 0}$ with a bis(alkynyl)xanthene connector 260 (Scheme 10). ${ }^{25}$ This metallotweezer acts as metalloligand in $261 \mathrm{~s} 10$ the presence of $\mathrm{Cu}^{+}, \mathrm{Tl}^{+}$, or $\mathrm{Ag}^{+}$, and we observed that the 262 coordination ability of the metalloligand was highly dependent 263 on the cation used. All of the coordination modes are highly 264 influenced by strong $\mathrm{M} \cdots \mathrm{Au}$ interactions. Coordination to $\mathrm{Cu}^{+} 265$ leads to a complex in which the metalloligand is coordinated in a 266 pincer form (11), with the copper atom bound to the two 267 
268 alkynyls and to the oxygen of the xanthene linker. In addition, 269 the copper(I) atom is also a very short distance from the $\mathrm{Au}$ 270 atoms, indicating strong metallophilic interactions. The reaction 271 of 10 with $\mathrm{Tl}^{+}$affords a complex in which the ligand acts as a 272 trans $-\kappa^{2}$ chelate ligand through two $\mathrm{Tl}-\mathrm{Au}$ metallophilic 273 interactions (12). The reaction with $\mathrm{Ag}^{+}$leads to a self274 assembled structure with two silver cations encased inside the 275 cavity of a duplex structure formed by two self-assembled 276 metallotweezers (13). The reason for the formation of this 277 structure is found in the core of the molecule, in which it can be 278 observed that the two silver atoms maximize all possible 279 interactions with the binding sites of the metalloligand (alkynyls 280 and gold atoms) with additional stabilization by the formation of 281 a Ag-Ag argentophilic bond (Scheme 10). ${ }^{25}$

282 The second strategy that we used to avoid the self-association 283 of the metallotweezers was to use a linker with two diverging 284 alkynyl groups. Complex 14 contains a bis(alkynyl)carbazole 285 connector with two pyrene-imidazolylidene-Au(I) arms. As 286 can be observed from the molecular structure of the complex 287 (Figure 1a), the two pyrene moieties are separated by a distance a)

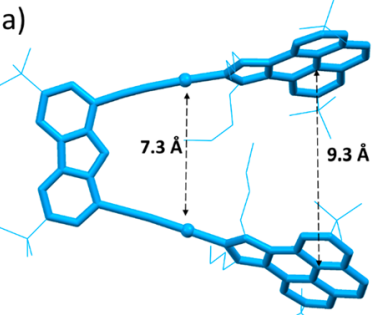

b)

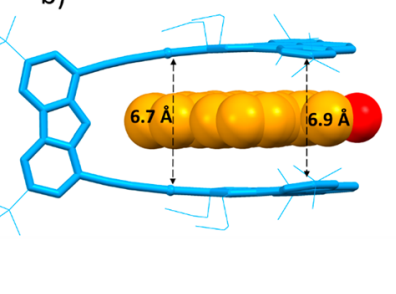

Figure 1. Molecular structures of (a) 14 and (b) 3-perylenylmethanol@14 (oxygen atom of guest in red).

288 of $9.3 \AA$, which is too large to facilitate the self-aggregation of the 289 complex. ${ }^{26}$ However, the two arms are flexible enough to reduce 290 this distance to $6.9 \AA$ so that the two pyrene arms can approach 291 the surface of a polyaromatic guest such as 3-perylenylmethanol 292 (Figure 1b), facilitating maximum face-to-face overlap.

293 Complex 14 was used for the recognition of a series of 294 polycyclic aromatic hydrocarbons (PAHs). The compound is 295 able to bind these planar polyaromatic guests as a result of the $296 \pi-\pi$-stacking interactions between the polyaromatic guests and 297 the pyrene moieties of the NHC ligand. ${ }^{26}$ In addition, the 298 presence of the $\mathrm{NH}$ group in the carbazole tether strengthens the 299 binding of those PAHs functionalized with groups capable of 300 hydrogen bonding, as concluded from our experimental and 301 density functional theory (DFT) studies. The association 302 constants of these guests are up to 1 order of magnitude larger 303 than those shown by unfunctionalized PAHs. For example, the 304 association constant between 14 and pyrene is $10 \mathrm{M}^{-1}$ in toluene, while the constant with 1-pyrenylmethanol is $340 \mathrm{M}^{-1}$, 305 as shown in Scheme 11. Similarly, the association constant of $14306 \mathrm{~s} 11$ with perylene is $145 \mathrm{M}^{-1}$, while the constant with 3- 307 perylenylmethanol is $1350 \mathrm{M}^{-1}$. ${ }^{26}$ These findings demonstrate 308 that the combination of $\pi-\pi$-stacking and hydrogen-bonding 309 interactions can be used for the rational design of more efficient 310 metalloreceptors.

311

\section{STRUCTURES WITH DI- AND TRI-NHC LIGANDS}

\subsection{Dimetallic Structures with Janus Di-NHCs}

In 2018 we studied the binding affinities of 15, a digold(I) 312 complex with a pyrenebis(imidazolylidene) ligand (Scheme 12), 313 s12

Scheme 12. Binding of 15 with Coronene and Effect on Catalysis

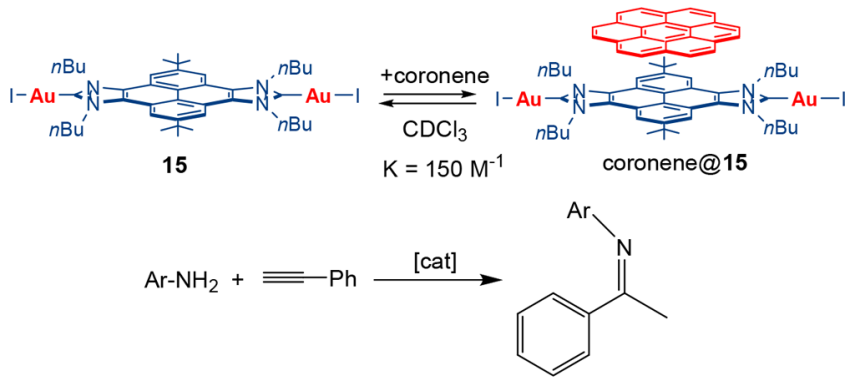

coronene@15 is $20-30 \%$ more active than 15

with a series of polycyclic aromatic hydrocarbons. ${ }^{27}$ The 314 presence of the pyrene moiety in the complex serves as a $\pi-\pi$ - 315 stacking platform for binding of PAHs, and an association 316 constant of $150 \mathrm{M}^{-1}$ was determined for the binding of $\mathbf{1 5}$ with 317 coronene in chloroform. Interestingly, the catalytic activity of 318 the complex toward the hydroamination of phenylacetylene 319 with primary amines was improved by $20-30 \%$ upon the 320 addition of coronene to the reaction medium. The study 321 demonstrated how the activity of a homogeneous catalyst can be 322 highly influenced by supramolecular interactions with an 323 external additive. ${ }^{27}$

We also prepared a di-NHC ligand connected by a 325 corannulene moiety that we coordinated to gold to afford 326 complex 16 (Scheme 13). We took advantage of the bowl- 327 s13 shaped nature of corannulene to use complex $\mathbf{1 6}$ as a receptor for 328 the recognition of fullerene $C_{60}$. Because of the excellent shape 329 complementarity, 16 and $\mathrm{C}_{60}$ showed an excellent binding 330 affinity in toluene solution, producing guest:host complexes 331 with stoichiometries of up to 1:3, as depicted in Scheme 13.

\subsection{Au-Based Metallorectangles and Metallocages}

The two examples shown in Schemes 12 and 13 constitute good 333 illustrations of how the introduction of extended $\pi$-conjugated 334

Scheme 11. Binding of 14 with Pyrene and 1-Pyrenylmethanol

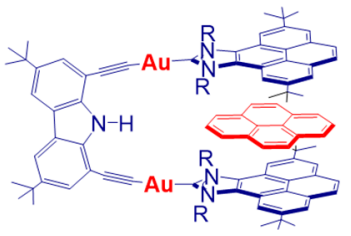

pyrene@14

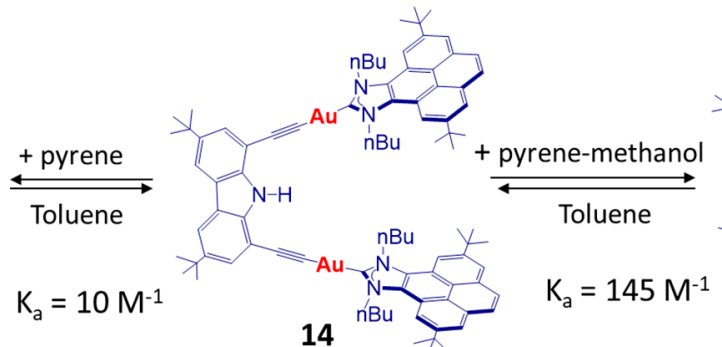

14

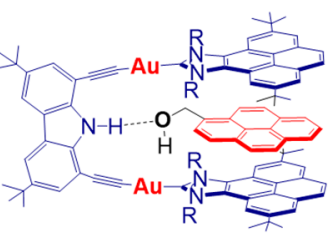

Pyrene-methanol@14 
Scheme 13. Reaction of 16 with $\mathrm{C}_{60}$; The DFT-Calculated Structure of the Product Is Shown
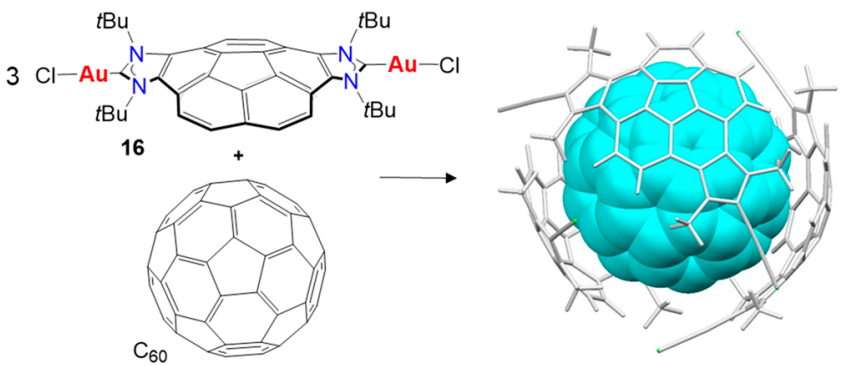

335 systems into the structure of Janus-type di-NHC ligands can 336 bring interesting properties into the resulting complexes due to 337 the establishment of $\pi-\pi$-stacking interactions with polyar338 omatic guests. The results are even more interesting if we 339 consider that the two examples shown before refer to complexes 340 with open structures lacking well-defined closed cavities. With 341 these results in hand, we thought that the introduction of this 342 type of ligand into the structure of closed metallocages should 343 produce metallosupramolecular assemblies with enhanced 344 host-guest chemistry abilities. Given our previous results on 345 the preparation of gold-based metallotweezers, we aimed to 346 obtain a set of new metallocages by replacing the mono-NHC 347 ligands by di- and tri-NHC ligands connected by extended $\pi$ 348 conjugated systems. Using this strategy and the bis(alkynyl)349 carbazole linker that we previously used for the preparation of 350 metallotweezer 14, we prepared metallorectangle $17,{ }^{28}$ trigonal351 prismatic metallocage $\mathbf{1 8},{ }^{29}$ and rhombohedral metallocyclo352 phane $19^{30}$ (Scheme 14). Interestingly, the nanosized nature of 353 the structures shown in Scheme 14, together with the presence 354 of the two cofacial polycyclic-conjugated panels in $\mathbf{1 7}$ and 18, 355 made these two latter assemblies very effective for the 356 encapsulation of polycyclic aromatic hydrocarbons. In partic357 ular, the hexagold prismatic cage $\mathbf{1 8}$ with the triphenylenetris358 (NHC) ligand has a "slotlike" cavity with a volume of $\sim 300 \AA^{3}$ 359 and a height of $7 \AA$. This cage shows a very large binding affinity 360 for coronene, which makes it serve as an excellent coronene 361 scavenger in $\mathrm{CH}_{2} \mathrm{Cl}_{2}{ }^{29}$ The perfect dimensional match between 36218 and coronene can be visualized in the structure shown in 363 Figure 2. On the other hand, metallorectangle 17 shows very

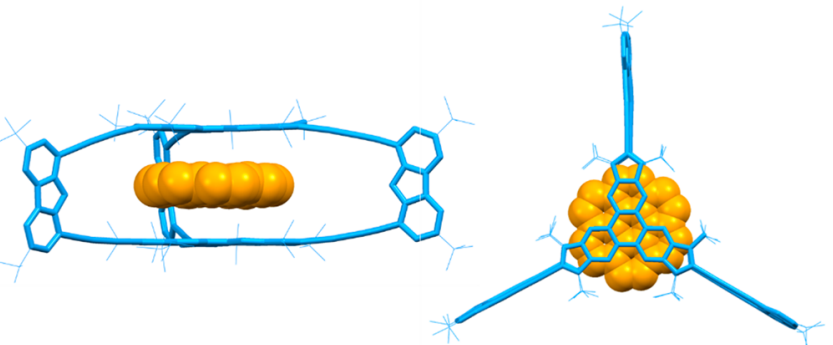

Figure 2. Two perspectives of the molecular structure of coronene@18.

high binding affinities for the encapsulation of planar PAHs in 364 $\mathrm{CH}_{2} \mathrm{Cl}_{2}$. The binding constants were found to increase 365 exponentially with the number of $\pi$ electrons of the guest as a 366 consequence of the enhancement of the host-guest face-to-face 367 overlap, ranging from $1.39<\log K<6.64$ for naphthalene 368 through coronene. ${ }^{28}$ These constants are among the highest 369 found for a metal-containing receptor and compare well with 370 those of the best organic-based cationic hosts. ${ }^{31}$ The large 371 binding affinities found for the case of $\mathbf{1 7}$ are due to the 372 incorporation of the two cofacial pyrene panels separated by 373 almost exactly $7 \AA$, thus providing an excellent dimensional 374 match that makes that the encapsulation take place at a 375 minimum energy cost due to the negligible structural distortions 376 suffered by both the host and guest. ${ }^{28}$

A very interesting feature of metallorectangle $\mathbf{1 7}$ is that it is 378 able to trap corannulene. As observed from the molecular 379 structure of corannulene@17 (Figure 3b), the encapsulation of $380 \mathrm{f} 3$ corannulene is accompanied by a significant compression of the 381 bowl-shaped guest (the bowl depth of free corannulene is $0.87 \AA, 382$ compared with $0.73 \AA$ for the encapsulated one) and 383 concomitant expansion of the host metallocage. The energy 384 cost due to this mutual induced-fit arrangement and the lack of 385 an effective $\pi-\pi$-stacking interaction over the convex surface of 386 the guest in corannulene@17 explain the reduced binding 387 affinity shown for corannulene compared with its related planar 388 20-electron $\mathrm{PAH}$, perylene (compare the structures of 389 perylene@17 and corannulene@17 in Figure 3).28

\section{Scheme 14. Gold-Based Metallosupramolecular Assemblies 17-19}

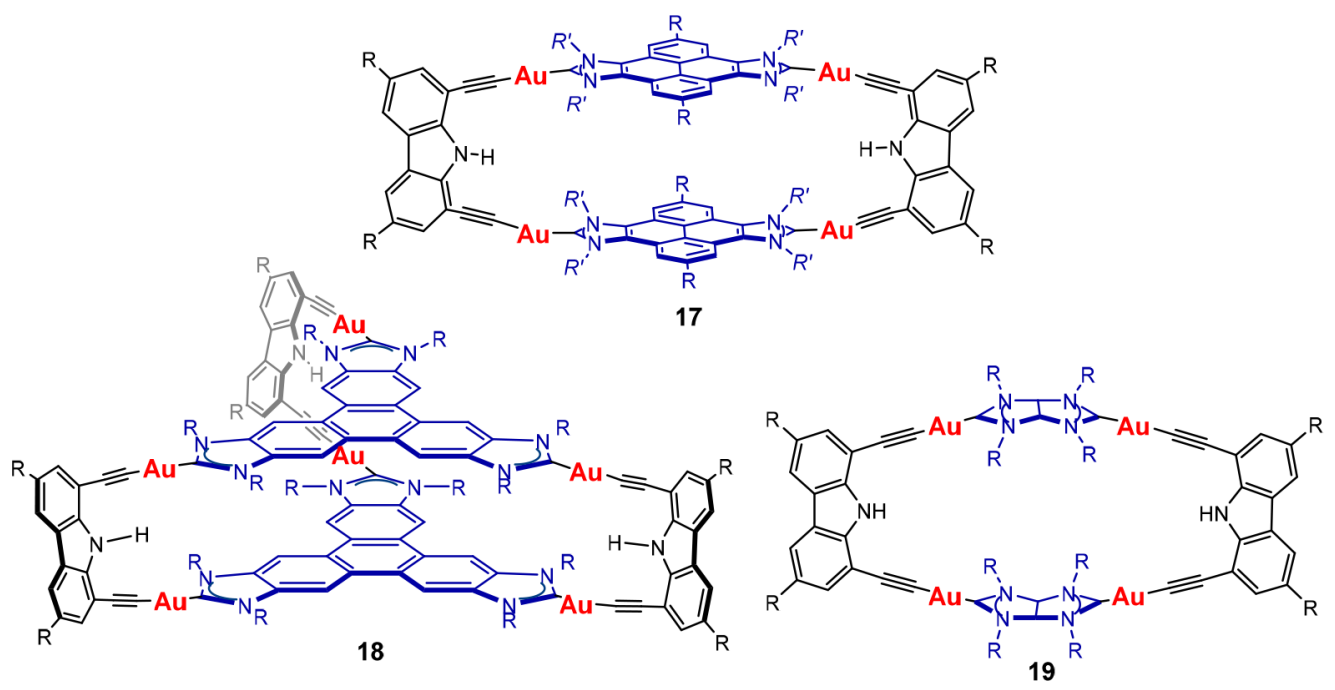




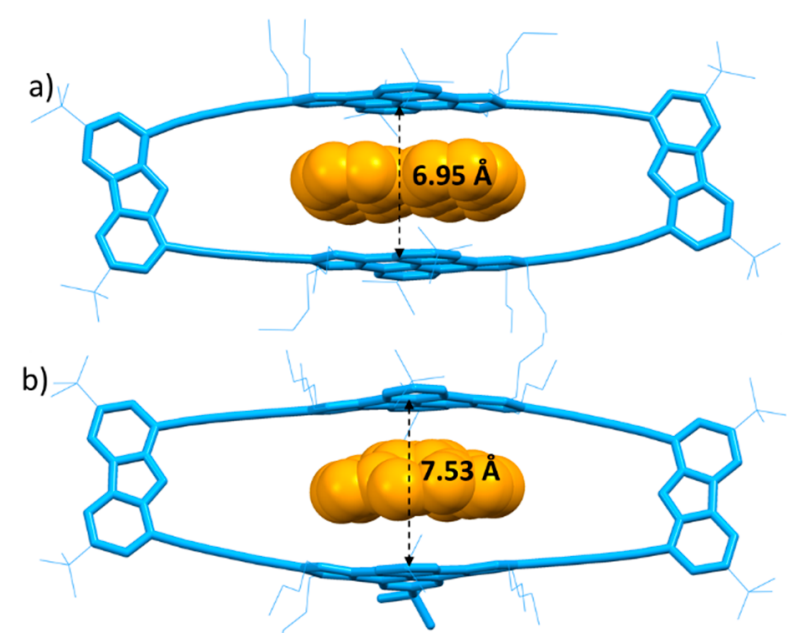

Figure 3. Molecular structures of (a) perylene@17 and (b) corannulene@17.

\subsection{Metallorectangles, Metallosquares, and Metallocages} 391 of $\mathrm{Ni}$ and $\mathrm{Pd}$

$392 \quad$ 3.3.1. Nickel. Pyrenebis(NHC) ligand C (Scheme 2) used in 393 the preparation of tetragold(I) complex 17 turned out to be a 394 very useful synthon for the preparation of metallosupramolec395 ular structures with metals other than gold. By the use of this di396 NHC ligand, two nickel-cornered metallorectangles were 397 prepared whose dimensions were modulated by using either 398 pyrazine or $4,4^{\prime}$-bipyridine. ${ }^{32}$ The metal-to-metal distance 399 established by the pyrenebis(imidazolylidene) ligands is $\sim 13$ $400 \AA$, while the distances along the $\mathrm{N}$-donor ligands are 7 and $11 \AA$ 401 for pyrazine and bipyridine, respectively (Scheme 15). These 402 molecular rectangles were used for the encapsulation of PAHs. 403 Because of their dimensions, pyrazine-containing rectangle $\mathbf{2 0}$ 404 was able to host only one molecule of the polyaromatic guest, 405 while rectangle 21 containing bipyridine was capable of hosting 406 up to two guest molecules. Figure 4 shows the molecular 407 structure of (pyrene) $)_{2} @ \mathbf{2 1}$, where it can be observed that 408 effective $\pi-\pi$-stacking interactions are established both between 409 the pyrene guest molecules and between the pyrene guests and 410 the pyrene moieties of the di-NHC ligands. The association 411 constants of the aromatic guests with both receptors were 412 determined in acetone- $d_{6}$. The results showed that a good fit 413 between the size of the PAH and the binding constant could be

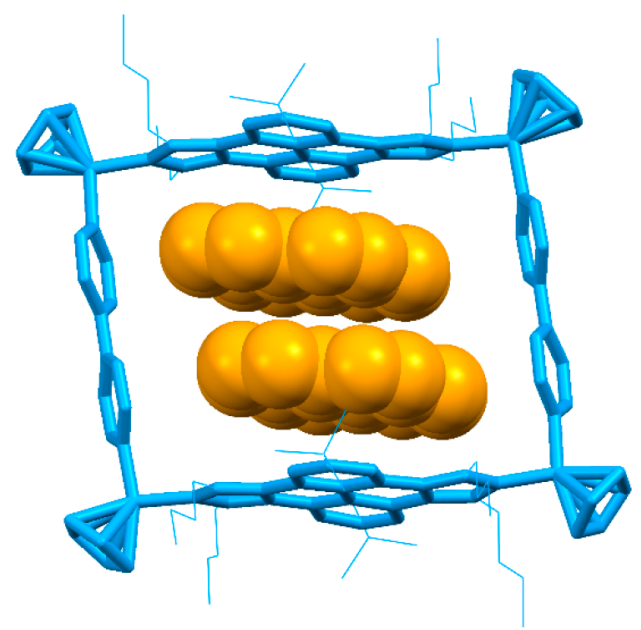

Figure 4. Molecular structure of (pyrene) ${ }_{2} @ 21$.

established by correlating the numbers of electrons of the guests 414 with their association constants. ${ }^{32}$

Using tripyridylpyrazine, we obtained trigonal prism 22416 (Scheme 16), ${ }^{33}$ which was used for the encapsulation of $417 \mathrm{~s} 16$

Scheme 16. Hexanickel Trigonal Prism 22 and

Representation of Its Ability to Encapsulate $C_{60}$ and $C_{70}$

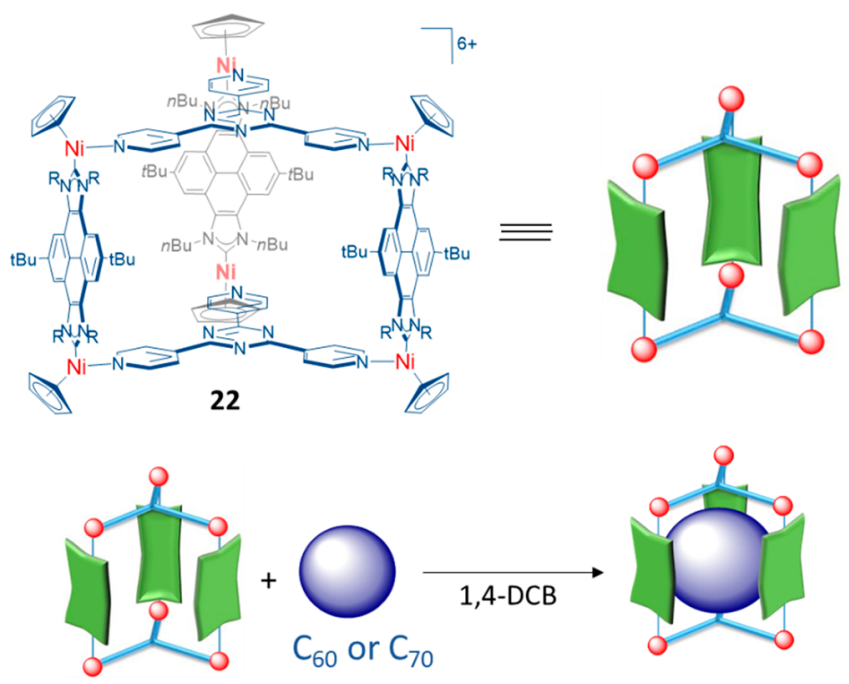

Scheme 15. Nickel-Cornered Metallorectangles 20 and 21

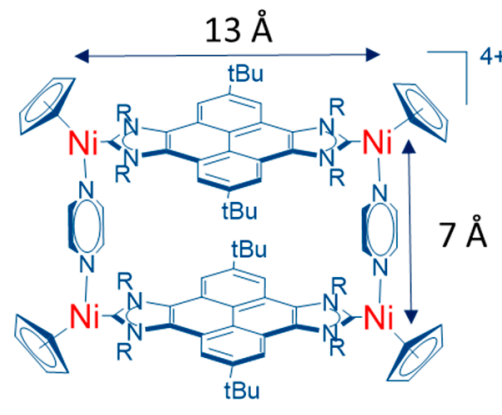

20

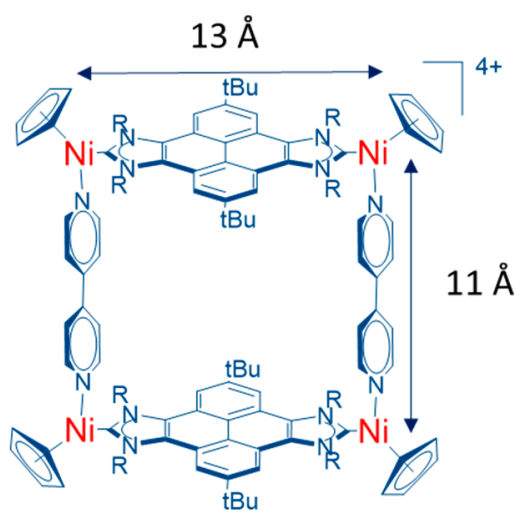

21 
Scheme 17. Palladium-Based Metallosquare 23 Used for the Encapsulation of $C_{60}$ and $C_{70}$

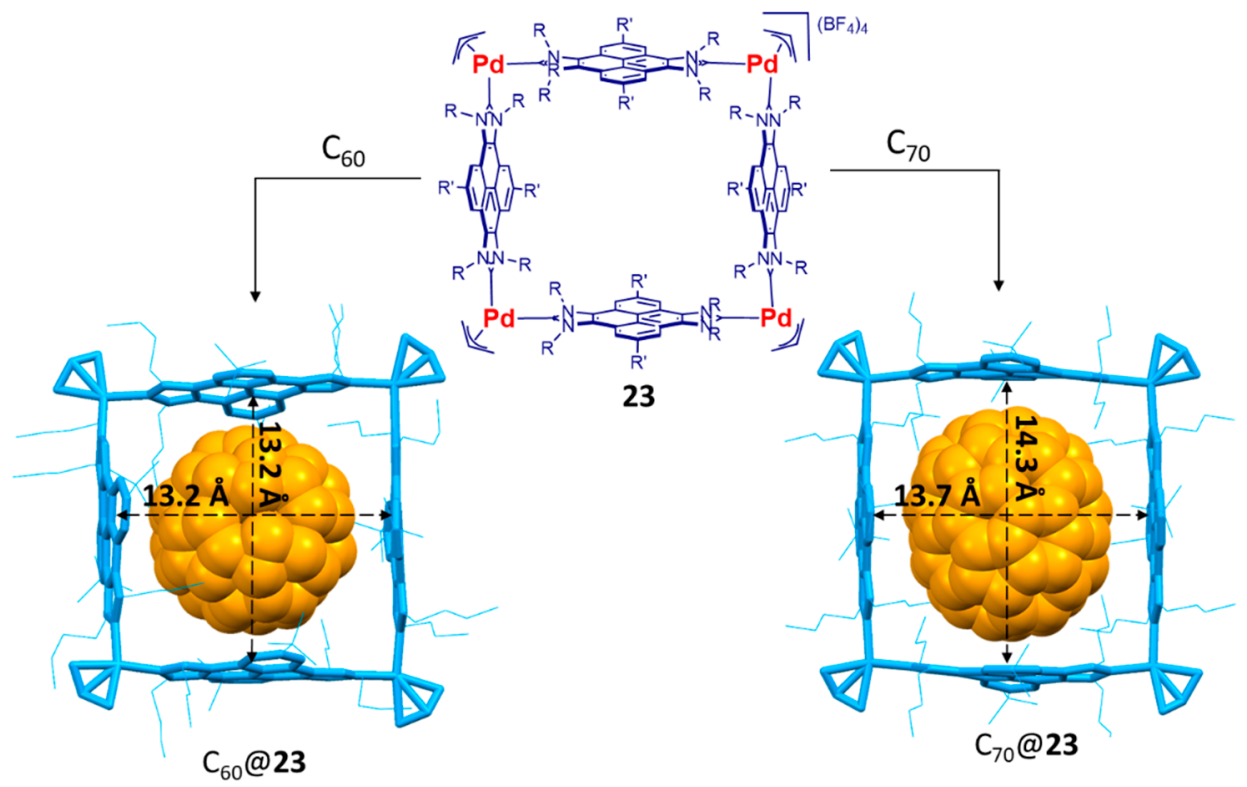

418 fullerenes $\mathrm{C}_{60}$ and $\mathrm{C}_{70}$. The study of the binding affinities 419 showed that the cage exhibits highly selective complexation of $420 \mathrm{C}_{70}$ over $\mathrm{C}_{60}$. The determination of the binding affinities at 421 different temperatures performed by ${ }^{1} \mathrm{H}$ NMR spectroscopy in 422 1,2-dichlorobenzene allowed the determination of the thermo423 dynamic values associated with the binding process. For the 424 association of $\mathrm{C}_{60}$ and $\mathrm{C}_{70}$, it was observed that the enthalpies 425 were low and positive as a consequence of the large solvation 426 enthalpies of both the free host and guests. For both fullerenes, 427 the association entropies were large and positive, thus indicating 428 that the process is entropically driven because of the desolvation 429 of both the host and guests. The higher entropy found for $\mathrm{C}_{70}$ 430 with respect to $\mathrm{C}_{60}$ is a consequence of the larger surface area of 431 the former, which means that a larger number of solvent 432 molecules are bound to $C_{70}$ relative to $C_{60} \cdot{ }^{33}$

433 3.3.2. Palladium. The same pyrenebis(imidazolylidene) 434 ligand was used for the preparation of palladium-conjoined 435 molecular square 23 (Scheme 17). ${ }^{34}$ The encapsulating 436 properties of this metallosquare are clearly determined by the 437 presence of the four pyrene panels, which endows the 438 compound a three-dimensional shape. This metallosquare was 439 used for the encapsulation of $\mathrm{C}_{60}$ and $\mathrm{C}_{70}$. The metallosquare is 440 shape-adaptable in the sense that it can adjust to accommodate 441 the size of the encapsulated fullerene. The pyrene panels bend in 442 order to adapt their shapes to maximize the face-to-face overlap 443 with the convex surface of the fullerene (see Scheme 17), and 444 this also modifies the guest-available volume of the cavity. For 445 example, the distances between the center points of opposite 446 pyrene panels in $\mathrm{C}_{60} @ 23$ are significantly shorter than the 447 related distances in $\mathrm{C}_{70} @ 23$ (Scheme 17). The cage exhibits a 448 higher affinity for $\mathrm{C}_{70}$ over $\mathrm{C}_{60}$, and the thermodynamic 449 parameters obtained from the determination of the association 450 constants at different temperatures show that the binding 451 process is entropically driven, and thus dominated by desolva452 tion rather than intrinsic interactions between the electron453 deficient fullerenes and the electron-rich faces of the pyrene 454 moieties of the metallosquare. ${ }^{34}$

455 An important feature of $\mathrm{C}_{60} @ 23$ and $\mathrm{C}_{70} @ 23$ is that both 456 host-guest complexes behaved as photochemically stable 457 singlet oxygen photosensitizers. ${ }^{35}$ Both host-guest complexes were used for the peroxidation of a series of cyclic and acyclic 458 alkenes at room temperature via visible-light-induced singlet 459 oxygen generation. By measuring the phosphorescence emission 460 spectra of singlet oxygen generated by the two complexes upon 461 irradiation with visible light, ${ }^{1} \mathrm{O}_{2}$ quantum yields of $\Phi_{\Delta}=0.23462$ and 0.41 were obtained for $\mathrm{C}_{60} @ 23$ and $\mathrm{C}_{70} @ 23$, respectively. 463 This explains why the activity shown by $\mathrm{C}_{70} @ 23$ in the 464 photocatalytic peroxidations was higher than that shown by 465 $\mathrm{C}_{60} @ 23{ }^{35}$ The photosensitizing properties of these two 466 fullerene-containing cages is explained by the excellent spin- 467 converting properties of fullerenes, which make them excep- 468 tional agents for singlet oxygen production (Scheme 18). These $469 \mathrm{~s} 18$ results are important because they underline the possibility that 470 other fullerene-containing supramolecular systems have the 471 potential to be used for similar catalytic reactions. 472

Another interesting feature of metallocage $\mathbf{2 3}$ is that it displays 473 a metal-to-metal distance of $13 \AA$, which is approximately 4474 times the distance for an effective $\pi-\pi$-stacking interaction and 475

Scheme 18. $\mathrm{C}_{60} @ 23$ and $\mathrm{C}_{70} @ 23$ Used as Photocatalyts for Peroxidation of Alkenes

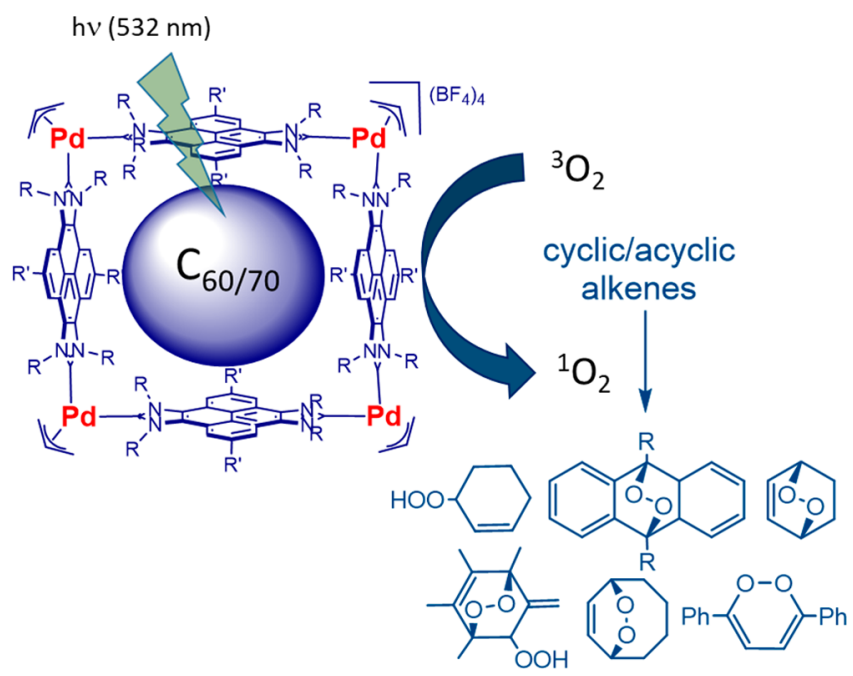


476 therefore optimum for encapsulating up to three polyaromatic 477 guests. In fact, the complex is able to encapsulate one molecule 478 of an electron-rich polycyclic aromatic hydrocarbon (pyrene, 479 triphenylene, or coronene) and two molecules of electron480 deficient $N, N^{\prime}$-dimethyl-naphthalenetetracarboxydiimide 481 (NTCDI). ${ }^{36}$ This forms quintuple $\pi$ stacks ordered in donor482 acceptor-donor-acceptor-donor (D-A-D-A-D) arrays 483 (Scheme 19), with the electron-rich pyrene fragments of the

Scheme 19. Quintuple D-A-D-A-D $\pi$ Stack Formed by Heteroguest Encapsulation in 23

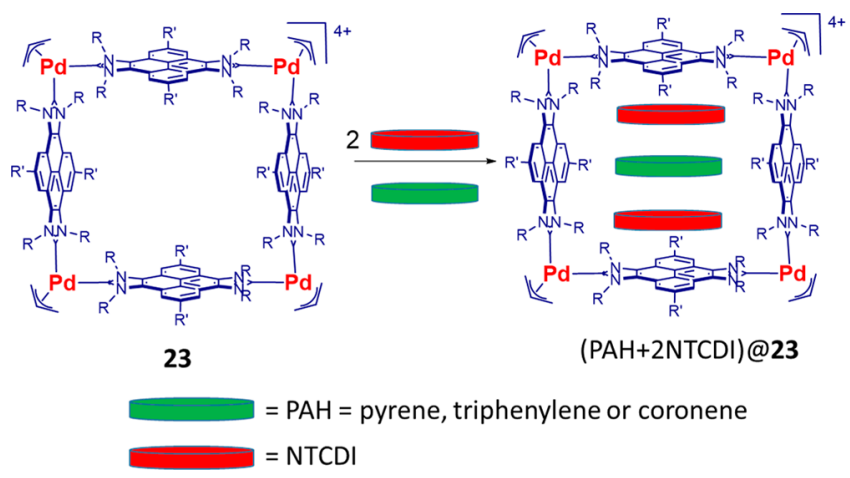

484 di-NHC ligand of the cage as bookend donors. The fact that 23 485 is able to trap large $\pi$-conjugated heteroguests to form quintuple $486 \pi$ stacks is interesting because most systems previously used for 487 the encapsulation of heteroguests are based on "closed" trigonal488 prismatic architectures, while ours is an "open" square structure.

\section{CONCLUSIONS AND OUTLOOK}

489 In this Account, we have described our most recent work on the 490 preparation of NHC-based metallosupramolecular assemblies 491 and their host-guest chemistry properties. We have tried to 492 emphasize that NHC ligands bearing planar polyaromatic 493 connectors offer a powerful tool for building hollow organo494 metallic supramolecular receptors, including metallotweezers, 495 metallosquares, metallorectangles, and trigonal-prismatic metal496 locages. The use of these systems as hosts for organic or 497 inorganic guests is directed by the intentional combination of 498 supramolecular interactions, including $\pi-\pi$-stacking, hydrogen499 bonding, and metallophilic interactions.

500 We once used the term "smart ligands" to refer to NHCs, 501 meaning that NHC chemistry has rapidly adapted to new times 502 and needs for novel reactivities, especially in the design of more 503 effective homogeneous catalysts. ${ }^{37}$ The results shown in this 504 Account illustrate how NHC ligands have also adapted to the 505 field of supramolecular chemistry, and therefore, NHC ligands 506 can be also considered smart in this field of chemistry. Probably 507 one of the advantages that needs to be highlighted here is that 508 now there is an extensive library of NHC ligands decorated with 509 rigid polyaromatic moieties that can provide clear advantages 510 over other traditional Werner-type ligands used in metal511 losupramolecular chemistry, for which the incorporation of 512 these planar polyconjugated fragments is much more difficult to 513 achieve. Another important feature that needs to be considered 514 is that most of the NHC-based supramolecular assemblies 515 described here are remarkably stable and can remain intact in 516 solution for days without signs of decomposition. This obviously 517 widens their potential use for practical applications. In this 518 regard, we expect that further effort will be applied in several 519 directions, for example toward the exploitation of the singlet oxygen generation properties of fullerene-containing supra- 520 molecular assemblies, not only from the photocatalytic point of 521 view but also as potential agents for clinical photodynamic 522 therapy (PDT). In addition, on the basis of the biomedical 523 activity shown by other Au- and Ag-containing NHC-based 524 supramolecular assemblies, ${ }^{16}$ studies can be directed to prospect 525 the biological applications of this type of system, possibly by 526 including in the NHC scaffolds further functionalities that can 527 target biological units (i.e., peptides), which to date has been 528 mostly explored with small molecules. ${ }^{38}$

Efforts can also be directed toward the reversible 530 encapsulation of homogeneous catalysts, which may be released 531 on demand by the addition of, for example, an additive guest 532 with a higher binding affinity with the receptor. Finally, the 533 possibility that supramolecular organometallic complexes can 534 form stable discrete multiple stacks may have important 535 implications for the design of nanoscale electronic devices 536 because enabling discrete $\pi$ stacks can facilitate the study of 537 charge transport at the molecular level. In summary, we hope 538 that the findings described in this Account will help advance in 539 the field of supramolecular organometallic host-guest chem- 540 istry.

\section{ASSOCIATED CONTENT}

Supporting Information

The Supporting Information is available free of charge at 544 https://pubs.acs.org/doi/10.1021/acs.accounts.0c00312. 545

Crystallographic data for 3-perylenylmethanol@14 (CIF) 546

\section{AUTHOR INFORMATION}

Eduardo Peris - Institute of Advanced Materials (INAM), Centro 549 de Innovación en Quimica Avanzada (ORFEO-CINQA), $\quad 550$ Universitat Jaume I, E-12071 Castellon, Spain; 이이.org/ 551 0000-0001-9022-2392; Email: eperis@uji.es

Authors

Susana Ibáñez - Institute of Advanced Materials (INAM), Centro 554 de Innovación en Quimica Avanzada (ORFEO-CINQA), $\quad 555$ Universitat Jaume I, E-12071 Castellon, Spain 556

Macarena Poyatos - Institute of Advanced Materials (INAM), 557 Centro de Innovación en Quimica Avanzada 558 (ORFEO-CINQA), Universitat Jaume I, E-12071 Castellon, 559 Spain; O orcid.org/0000-0003-2000-5231

Complete contact information is available at: https://pubs.acs.org/10.1021/acs.accounts.0c00312

\section{Author Contributions}

The manuscript was written through contributions of all 564 authors. All of the authors approved the final version of the 565 manuscript.

Notes

The authors declare no competing financial interest.

Biographies

Susana Ibáñez graduated in Chemistry in 2001 at the University of 570 Zaragoza. She received her Ph.D. degree with European Doctorate in 571 2007 at the University of Zaragoza. She then moved to Bari (Italy) as a 572 postdoctoral fellow under the supervision of Prof. Piero Mastrorilli. In 573 2009 she joined Prof. Bernhard Lippert at Tecnische Universität 574 
575 Dortmund, where she stayed for 2 years. In 2014 she joined Prof. 576 Eduardo Peris' group at Universitat Jaume I as an associate researcher.

577 Macarena Poyatos graduated in Chemistry at Universitat Jaume I 578 (Castellón, Spain). She received her Ph.D. degree in 2005 at Universitat 579 Jaume I under the supervision of Prof. Eduardo Peris. She then moved 580 to Strasbourg, where she joined the group supervised by Prof. Lutz H. 581 Gade and Dr. Stéphane Bellemin-Laponnaz. In 2006 she joined Prof. 582 Robert H. Crabtree's group at Yale University, where she stayed for 2 583 years. In 2008 she returned to Universitat Jaume I, where she currently 584 holds a position as an associate professor.

585 Eduardo Peris received his Ph.D. degree in Chemistry in 1991 at the 586 Universidad de Valencia. In 1994 he joined Robert Crabtree's group at 587 Yale University, where he stayed for 2 years. In October 1995 he moved 588 to Universitat Jaume I, where he currently holds a position as a full 589 professor. The current interest of his group is the development of 590 organometallic-based supramolecular systems for the development of 591 host-guest receptors and improved catalysts.

\section{ACKNOWLEDGMENTS}

593 We gratefully acknowledge financial support from the Ministerio 594 de Ciencia e Innovación (PGC2018-093382-B-I00) and 595 Universitat Jaume I (UJI-B2017-07 and UJI-A2017-02). E.P. 596 thanks the Alexander von Humboldt Foundation for a 597 Humboldt Research Award.

\section{$598-$ REFERENCES}

599 (1) (a) Chakrabarty, R.; Mukherjee, P. S.; Stang, P. J. Supramolecular 600 Coordination: Self-Assembly of Finite Two- and Three-Dimensional 601 Ensembles. Chem. Rev. 2011, 111, 6810-6918. (b) Smulders, M. M. J.; 602 Riddell, I. A.; Browne, C.; Nitschke, J. R. Building on architectural 603 principles for three-dimensional metallosupramolecular construction. 604 Chem. Soc. Rev. 2013, 42, 1728-1754. (c) Constable, E. C. Expanded 605 ligands - An assembly principle for supramolecular chemistry. Coord. 606 Chem. Rev. 2008, 252, 842-855. (d) Wang, W.; Wang, Y. X.; Yang, H. 607 B. Supramolecular transformations within discrete coordination-driven 608 supramolecular architectures. Chem. Soc. Rev. 2016, 45, 2656-2693.

609 (2) (a) Cook, T. R.; Stang, P. J. Recent Developments in the 610 Preparation and Chemistry of Metallacycles and Metallacages via 611 Coordination. Chem. Rev. 2015, 115, 7001-7045. (b) Castilla, A. M.; 612 Ramsay, W. J.; Nitschke, J. R. Stereochemistry in Subcomponent Self613 Assembly. Acc. Chem. Res. 2014, 47, 2063-2073. (c) McConnell, A. J.; 614 Wood, C. S.; Neelakandan, P. P.; Nitschke, J. R. Stimuli-Responsive 615 Metal-Ligand Assemblies. Chem. Rev. 2015, 115, 7729-7793. 616 (d) Fujita, M. Metal-directed self-assembly of two- and three617 dimensional synthetic receptors. Chem. Soc. Rev. 1998, 27, 417-425. 618 (3) (a) Otte, M. Size-Selective Molecular Flasks. ACS Catal. 2016, 6, 619 6491-6510. (b) Yoshizawa, M.; Klosterman, J. K.; Fujita, M. 620 Functional Molecular Flasks: New Properties and Reactions within 621 Discrete, Self-Assembled Hosts. Angew. Chem., Int. Ed. 2009, 48, 34186223438

623 (4) Poyatos, M.; Mata, J. A.; Peris, E. Complexes with poly(N624 heterocyclic carbene) ligands: structural features and catalytic 625 applications. Chem. Rev. 2009, 109, 3677-3707.

626 (5) (a) Gan, M. M.; Liu, J. Q.; Zhang, L.; Wang, Y. Y.; Hahn, F. E.; 627 Han, Y. F. Preparation and Post-Assembly Modification of Metal628 losupramolecular Assemblies from Poly(N-Heterocyclic Carbene) 629 Ligands. Chem. Rev. 2018, 118, 9587-9641. (b) Sinha, N.; Hahn, F. 630 E. Metallosupramolecular Architectures Obtained from Poly-N631 heterocyclic Carbene Ligands. Acc. Chem. Res. 2017, 50, 2167-2184. 632 (c) Pöthig, A.; Casini, A. Recent Developments of Supramolecular 633 Metal-Based Structures for Applications in Cancer Therapy and 634 Imaging. Theranostics 2019, 9, 3150-3169.

635 (6) (a) Conrady, F. M.; Fröhlich, R.; Schulte to Brinke, C.; Pape, T.; $636 \mathrm{Hahn}$, F. E. Stepwise Formation of a Molecular Square with Bridging 637 NH, O-Substituted Dicarbene Building Blocks. J. Am. Chem. Soc. 2011,
133, 11496-11499. (b) Schmidtendorf, M.; Pape, T.; Hahn, F. E. 638 Stepwise Preparation of a Molecular Square from NR, NR- and NH, O- 639 Substituted Dicarbene Building Blocks. Angew. Chem., Int. Ed. 2012, 51, 640 2195-2198. (c) Mejuto, C.; Guisado-Barrios, G.; Gusev, D.; Peris, E. 641 First homoleptic MIC and heteroleptic NHC-MIC coordination cages 642 from 1,3,5-triphenylbenzene-bridged tris-MIC and tris-NHC ligands. 643 Chem. Commun. 2015, 51, 13914-13917.

(7) (a) Radloff, C.; Gong, H. Y.; Schulte to Brinke, C.; Pape, T.; 645 Lynch, V. M.; Sessler, J. L.; Hahn, F. E. Metal-Dependent Coordination 646 Modes Displayed by Macrocyclic Polycarbene Ligands. Chem. - Eur. J. 647 2010, 16, 13077-13081. (b) Rit, A.; Pape, T.; Hahn, F. E. Self- 648 Assembly of Molecular Cylinders from Polycarbene Ligands and $\mathrm{Ag}^{\mathrm{I}}$ or 649 Au'. J. Am. Chem. Soc. 2010, 132, 4572-4573. (c) Rit, A.; Pape, T.; 650 Hepp, A.; Hahn, F. E. Supramolecular Structures from Polycarbene 651 Ligands and Transition Metal Ions. Organometallics 2011, 30, 334- 652 347. (d) Wang, D. H.; Zhang, B. G.; He, C.; Wu, P. Y.; Duan, C. Y. A 653 new chiral N-heterocyclic carbene silver(I) cylinder: synthesis, crystal 654 structure and catalytic properties. Chem. Commun. 2010, 46, 4728- 655 4730. (e) Segarra, C.; Guisado-Barrios, G.; Hahn, F. E.; Peris, E. 656 Hexanuclear cylinder-shaped assemblies of silver and gold from 657 benzene-hexa-N-heterocyclic carbenes. Organometallics 2014, 33, 658 5077-5080. (f) Sinha, N.; Roelfes, F.; Hepp, A.; Mejuto, C.; Peris, 659 E.; Hahn, F. E. Synthesis of Nanometer-Sized Cylinder-Like Structures 660 from a 1,3,5-Triphenylbenzene-Bridged Tris-NHC Ligand and $\mathrm{Ag}^{\mathrm{I}}, 661$ $\mathrm{Au}^{\mathrm{I}}$, and $\mathrm{Cu}^{\mathrm{I}}$. Organometallics 2014, 33, 6898-6904. (g) Sinha, N.; 662 Stegemann, L.; Tan, T. T. Y.; Doltsinis, N. L.; Strassert, C. A.; Hahn, F. 663 E. Turn-On Fluorescence in Tetra-NHC Ligands by Rigidification 664 through Metal Complexation: An Alternative to Aggregation-Induced 665 Emission. Angew. Chem., Int. Ed. 2017, 56, 2785-2789. (h) Li, Y.; An, 666 Y. Y.; Fan, J. Z.; Liu, X. X.; Li, X.; Hahn, F. E.; Wang, Y. Y.; Han, Y. F. 667 Strategy for the Construction of Diverse Poly-NHC-Derived 668 Assemblies and Their Photoinduced Transformations. Angew. Chem., 669 Int. Ed. 2020, 59, 10073-10080.

670

(8) (a) Mas-Marza, E.; Mata, J. A.; Peris, E. Triazolediylidenes: A 671 versatile class of ligands for the preparation of discrete molecules of 672 homo- and hetero-binuclear complexes for improved catalytic 673 applications. Angew. Chem., Int. Ed. 2007, 46, 3729-3731. (b) Prades, 674 A.; Peris, E.; Alcarazo, M. Pyracenebis(imidazolylidene): a new Janus- 675 type biscarbene and its coordination to rhodium and iridium. 676 Organometallics 2012, 31, 4623-4626. (c) Gonell, S.; Poyatos, M.; 677 Peris, E. Pyrene-Based Bisazolium Salts: From Luminescence Proper- 678 ties to Janus-Type Bis-N-Heterocyclic Carbenes. Chem. - Eur. J. 2014, 679 20, 9716-9724. (d) Gonell, S.; Poyatos, M.; Peris, E. Triphenylene- 680 Based Tris(N-Heterocyclic Carbene) Ligand: Unexpected Catalytic 681 Benefits. Angew. Chem., Int. Ed. 2013, 52, 7009-7013. (e) Valdes, H.; 682 Poyatos, M.; Peris, E. A Nanosized Janus Bis-N-heterocyclic Carbene 683 Ligand Based on a Quinoxalinophenanthrophenazine Core, and Its 684 Coordination to Iridium. Organometallics 2015, 34, 1725-1729. 685 (f) Ibáñez, S.; Poyatos, M.; Peris, E. A $D_{3 h}$-symmetry hexaazatriphe- 686 nylene-tris-N-heterocyclic carbene ligand and its coordination to 687 iridium and gold: preliminary catalytic studies. Chem. Commun. 2017, 688 53, 3733-3736. (g) Valdes, H.; Poyatos, M.; Peris, E. A Pyrene-Based 689 N-Heterocyclic Carbene: Study of Its Coordination Chemistry and 690 Stereoelectronic Properties. Organometallics 2014, 33, 394-401. 691 (9) (a) Boydston, A. J.; Bielawski, C. W. Bis(imidazolylidene)s as 692 modular building blocks for monomeric and macromolecular organo- 693 metallic materials. Dalton Trans. 2006, 4073-4077. (b) Boydston, A. J.; 694 Williams, K. A.; Bielawski, C. W. A modular approach to main-chain 695 organometallic polymers. J. Am. Chem. Soc. 2005, 127, 12496-12497. 696 (10) Segarra, C.; Linke, J.; Mas-Marza, E.; Kuck, D.; Peris, E. A C C $^{-} 697$ symmetrical tribenzotriquinacene-based threefold N-heterocyclic 698 carbene. Coordination to rhodium(I) and stereoelectronic properties. 699 Chem. Commun. 2013, 49, 10572-10574.

(11) Radloff, C.; Weigand, J. J.; Hahn, F. E. A tetranuclear molecular 701 rectangle from four gold(I) atoms linked by dicarbene and diphosphine 702 ligands. Dalton Trans. 2009, 9392-9394.

(12) (a) Schmidtendorf, M.; Schulte to Brinke, C.; Hahn, F. E. 704 Benzodicarbene-bridged dinuclear complexes as building blocks for 705 metalosupramolecular architectures. J. Organomet. Chem. 2014, 751, 706 
707 620-627. (b) Sinha, A.; Roelfes, F.; Hepp, A.; Hahn, E. F. Single-Step 708 Synthesis of Organometallic Molecular Squares from NR, NR', NR", 709 NR'"'-Substituted Benzobiscarbenes. Chem. - Eur. J. 2017, 23, 59397105942 .

711 (13) Schmidtendorf, M.; Pape, T.; Hahn, F. E. Molecular rectangles 712 from platinum(II) and bridging dicarbene, diisocyanide and 4,4'713 bipyridine ligands. Dalton Trans. 2013, 42, 16128-16141.

714 (14) Radloff, C.; Hahn, F. E.; Pape, T.; Fröhlich, R. Supramolecular 715 structures from mono and dimetalated biscarbene ligands. Dalton 716 Trans. 2009, 7215-7222.

717 (15) (a) Altmann, P. J.; Pöthig, A. Pillarplexes: A Metal-Organic 718 Class of Supramolecular Hosts. J. Am. Chem. Soc. 2016, 138, 13171719 13174. (b) Altmann, P. J.; Pöthig, A. A pH-Dependent, Mechanically 720 Interlocked Switch: Organometallic [2]Rotaxane vs. Organic [3]721 Rotaxane. Angew. Chem., Int. Ed. 2017, 56, 15733-15736.

722 (16) Pöthig, A.; Ahmed, S.; Winther-Larsen, H. C.; Guan, S.; Altmann, 723 P. J.; Kudermann, J.; Santos Andresen, A. M.; Gjøen, T.; Høgmoen 724 Åstrand, O. A. Antimicrobial Activity and Cytotoxicity of $\mathrm{Ag}(\mathrm{I})$ and $725 \mathrm{Au}(\mathrm{I})$ Pillarplexes. Front. Chem. 2018, 6, 584.

726 (17) Peris, E. Polyaromatic N-heterocyclic carbene ligands and pi727 stacking. Catalytic consequences. Chem. Commun. 2016, 52, 57777285787 .

729 (18) (a) Hardouin-Lerouge, M.; Hudhomme, P.; Salle, M. Molecular 730 clips and tweezers hosting neutral guests. Chem. Soc. Rev. 2011, 40, 30731 43. (b) Klarner, F. G.; Kahlert, B. Molecular tweezers and clips as 732 synthetic receptors. Molecular recognition and dynamics in receptor733 substrate complexes. Acc. Chem. Res. 2003, 36, 919-932. (c) Klarner, F. 734 G.; Schrader, T. Aromatic Interactions by Molecular Tweezers and 735 Clips in Chemical and Biological Systems. Acc. Chem. Res. 2013, 46, 736 967-978. (d) Leblond, J.; Petitjean, A. Molecular Tweezers: Concepts 737 and Applications. ChemPhysChem 2011, 12, 1043-1051.

738 (19) (a) Alvarez, C. M.; Garcia-Escudero, L. A.; Garcia-Rodriguez, R.; 739 Martin-Alvarez, J. M.; Miguel, D.; Rayon, V. M. Enhanced association 740 for C-70 over C-60 with a metal complex with corannulene derivate 741 ligands. Dalton Trans. 2014, 43, 15693-15696. (b) Tanaka, Y.; Wong, 742 K. M. C.; Yam, V. W. W. Platinum-Based Phosphorescent Double743 Decker Tweezers: A Strategy for Extended Heterologous Metal-Metal 744 Interactions. Angew. Chem., Int. Ed. 2013, 52, 14117-14120. 745 (c) Tanaka, Y.; Wong, K. M. C.; Yam, V. W. W. Host-Guest 746 Interactions of Phosphorescent Molecular Tweezers Based on an 747 Alkynylplatinum(II) Terpyridine System with Polyaromatic Hydro748 carbons. Chem. - Eur. J. 2013, 19, 390-399. (d) Fu, T. F.; Han, Y. F.; 749 Ao, L.; Wang, F. Bis alkynylplatinum(II) Terpyridine Molecular 750 Tweezer/Guest Recognition Enhanced by Intermolecular Hydrogen 751 Bonds: Phototriggered Complexation via the "Caging" Strategy. 752 Organometallics 2016, 35, 2850-2853. (e) Doistau, B.; Rossi753 Gendron, C.; Tron, A.; McClenaghan, N. D.; Chamoreau, L. M.; 754 Hasenknopf, B.; Vives, G. Switchable platinum-based tweezers with Pt755 Pt bonding and selective luminescence quenching. Dalton Trans. 2015, 756 44, 8543-8551. (f) Chan, A. K. W.; Yam, V. W. W. Precise Modulation 757 of Molecular Building Blocks from Tweezers to Rectangles for 758 Recognition and Stimuli-Responsive Processes. Acc. Chem. Res. 2018, 759 51, 3041-3051. (g) Crowley, J. D.; Bosnich, B. Molecular recognition: 760 Use of metal-containing molecular clefts for supramolecular self761 assembly and host-guest formation. Eur. J. Inorg. Chem. 2005, 2005, 762 2015-2025.

763 (20) Nuevo, D.; Gonell, S.; Poyatos, M.; Peris, E. Platinum-Based 764 Organometallic Folders for the Recognition of Electron-Deficient 765 Aromatic Substrates. Chem. - Eur. J. 2017, 23, 7272-7277.

766 (21) Ibáñez, S.; Poyatos, M.; Peris, E. Cation-Driven Self-Assembly of 767 a Gold(I)-Based Metallo-Tweezer. Angew. Chem., Int. Ed. 2017, 56, 768 9786-9790.

769 (22) Ibáñez, S.; Peris, E. Chemically Tunable Formation of Different 770 Discrete, Oligomeric, and Polymeric Self-Assembled Structures from 771 Digold Metallotweezers. Chem. - Eur. J. 2018, 24, 8424-8431.

772 (23) Ibáñez, S.; Peris, E. A Matter of Fidelity: Self-Sorting Behavior of 773 Di-Gold Metallotweezers. Chem. - Eur. J. 2019, 25, 8254-8258.

774 (24) Wang, Y. S.; Feng, T.; Wang, Y. Y.; Hahn, F. E.; Han, Y. F. Homo775 and Heteroligand Poly-NHC Metal Assemblies: Synthesis by
Narcissistic and Social Self-Sorting. Angew. Chem., Int. Ed. 2018, 57, 776 $15767-15771$.

(25) Ibáñez, S.; Poyatos, M.; Peris, E. The Complex Coordination 778 Landscape of a Digold(I) U-Shaped Metalloligand. Angew. Chem., Int. 779 Ed. 2018, 57, 16816-16820.

(26) Biz, C.; Ibáñez, S.; Poyatos, M.; Gusev, D.; Peris, E. Gold(I) 781 Metallo-Tweezers for the Recognition of Functionalized Polycyclic 782 Aromatic Hydrocarbons by Combined pi-pi Stacking and H-Bonding. 783 Chem. - Eur. J. 2017, 23, 14439-14444.

(27) Nuevo, D.; Poyatos, M.; Peris, E. A Dinuclear Au(I) Complex 785 with a Pyrene-di-N-heterocyclic Carbene Linker: Supramolecular and 786 Catalytic Studies. Organometallics 2018, 37, 3407-3411.

(28) Ibáñez, S.; Peris, E. Dimensional Matching versus Induced-Fit 788 Distortions: Binding Affinities of Planar and Curved Polyaromatic 789 Hydrocarbons with a Tetragold Metallorectangle. Angew. Chem., Int. 790 Ed. 2020, 59, 6860-6865.

(29) Ibáñez, S.; Peris, E. A Rigid Trigonal-Prismatic Hexagold 792 Metallocage That Behaves as a Coronene Trap. Angew. Chem., Int. Ed. 793 2019, 58, 6693-6697.

(30) Gutierrez-Blanco, A.; Ibáñez, S.; Hahn, F. E.; Poyatos, M.; Peris, 795 E. A Twisted Tetragold Cyclophane from a Fused Bis-Imidazolindiy- 796 lidene. Organometallics 2019, 38, 4565-4569.

(31) (a) Dale, E. J.; Vermeulen, N. A.; Thomas, A. A.; Barnes, J. C.; 798 Juricek, M.; Blackburn, A. K.; Strutt, N. L.; Sarjeant, A. A.; Stern, C. L.; 799 Denmark, S. E.; Stoddart, J. F. ExCage. J. Am. Chem. Soc. 2014, 136, 800 10669-10682. (b) Barnes, J. C.; Juricek, M.; Strutt, N. L.; Frasconi, M.; 801 Sampath, S.; Giesener, M. A.; McGrier, P. L.; Bruns, C. J.; Stern, C. L.; 802 Sarjeant, A. A.; Stoddart, J. F. ExBox: A Polycyclic Aromatic 803 Hydrocarbon Scavenger. J. Am. Chem. Soc. 2013, 135, 183-192. 804

(32) Martinez-Agramunt, V.; Ruiz-Botella, S.; Peris, E. Nickel- 805 Cornered Molecular Rectangles as Polycyclic Aromatic Hydrocarbon 806 Receptors. Chem. - Eur. J. 2017, 23, 6675-6681.

(33) Martinez-Agramunt, V.; Gusev, D. G.; Peris, E. A Shape- 808 Adaptable Organometallic Supramolecular Coordination Cage for the 809 Encapsulation of Fullerenes. Chem. - Eur. J. 2018, 24, 14802-14807. 810 (34) Martinez-Agramunt, V.; Eder, T.; Darmandeh, H.; Guisado- 811 Barrios, G.; Peris, E. A Size-Flexible Organometallic Box for the 812 Encapsulation of Fullerenes. Angew. Chem., Int. Ed. 2019, 58, 5682- 813 5686.

(35) Martinez-Agramunt, V.; Peris, E. Photocatalytic Properties of a 815 Palladium Metallosquare with Encapsulated Fullerenes via Singlet 816 Oxygen Generation. Inorg. Chem. 2019, 58, 11836-11842.

(36) Martinez-Agramunt, V.; Peris, E. A palladium-hinged organo- 818 metallic square with a perfect-sized cavity for the encapsulation of three 819 heteroguests. Chem. Commun. 2019, 55, 14972-14975.

(37) Peris, E. Smart N-heterocyclic carbene ligands in catalysis. Chem. 821 Rev. 2018, 118, 9988-10031.

(38) Meier-Menches, S. M.; Casini, A. Design Strategies and 823 Medicinal Applications of Metal-Peptidic Bioconjugates. Bioconjugate 824 Chem. 2020, 31, 1279-1288. 